\section{Porträt und Selbstbildnis}

Keine künstlerische Bildgattung spiegelt den Prozeß der Individualisierung im Übergang vom Mittelalter zur Renaissance so vielgestaltig wie das Porträt und Selbstporträt: Schon rein zahlenmäßig betrachtet läßt sich die Erfolgsgeschichte des Porträts ausgehend von vereinzelten Bildnissen im 12., 13. und 14. Jahrhundert bis zur überwältigenden Flut an Porträtdarstellungen im 15. und 16. Jahrhundert erkennen. Im Verlauf dieses Prozesses erfährt das Porträt auch eine tiefreichende Verwandlung seiner gesellschaftlichen Funktionen, vom elitären Herrschaftsbildnis des Hohen Mittelalters (Abb. 34) zum Auftreten von Bildnissen als gesellschaftlichem Breitenphänomen seit dem späten 15. Jahrhundert ${ }^{1}$.

Die Struktur dieses kulturgeschichtlichen Prozesses ist freilich nicht zuvörderst von äußeren Faktoren abzuleiten, sondern ist wesentlich von den künstlerischen und medialen Bedingungen, welche die Künstler zur Darstellung eines individuellen Menschen nach und nach erschlossen haben, getragen. Auch ist dieser Prozeß nicht naiverweise auf einen Prozeß der Zunahme an »Ähnlichkeit« der Bildnisse im Sinne einer linearen Fortschrittsgeschichte der mimetischen Darstellungsfähigkeit der Künstler zu begradigen ${ }^{2}$. Vielmehr gilt es, die Darstellungsmittel und -weisen im Porträt selbst als spezifisches Erkenntnismittel, als "Sprache« sui generis zu analysieren, um zu entdecken, wie sich das historisch verändernde Selbstverständnis der Menschen in diesen Darstellungen artikuliert. Erst wenn man auf die ästhetische Rationalität der malerischen und künstlerischen Mittel jenseits der vordergründigen Frage der äußerlichen Ähnlichkeit achtet, erschließen sich Porträt und Selbstporträt in einem vertieften Sinn als Dokumente eines geistesgeschichtlichen Prozesses menschlicher Selbstreflexion. Denn genaugenommen läßt sich das, was die Künstler im Bildnis und Selbstbildnis am Übergang zur frühen Neuzeit mit neuen Mitteln vom individuellen Menschen zur Anschauung bringen, nicht ausschließlich auf ein künstlerisches Problem der Darstellung von Sichtbarkeit reduzieren, sondern bildet vielmehr die komplexe Umschreibung einer unsichtbaren Dimension am Menschen mit visuellen Mitteln. Viel lückenloser und umfassender als im Medium der schriftlichen Quellen dokumentiert die Genese des Porträts als gleichsam gemalte Anthropologie den historischen Prozeß der Individualisierung, wie er im folgenden mit exemplarischen Betrachtungen von seinen Anfängen im Hohen Mittelalter ausgehend bis ins 16. Jahrhundert zu umreißen ist.

Die historische Struktur dieses Prozesses ist in der älteren Forschung nicht selten als unvermitteltes $>$ Ereignis< gedeutet worden: So sprach Jacob Burckhardt pointiert von der *Entdeckung des Menschen in der italienischen Renaissance ${ }^{3}$. Andere Forscher haben die Entstehung des Porträts in der frühen Neuzeit als die künstlerische Tat des altniederländischen Malers Jan van Eyck beschrieben ${ }^{4}$. Auch wenn die Bedeutung

CHRISTOPH WAGNER

hierzu Jacob Burckhardt: Beiträge zur Kunstgeschichte in Italien. Das Altarbild Das Porträt in der Malerei-Die Sammler, Basel 1898, S. 145ff. Enrico Castelnuovo: Das künstlerische Porträt in der Gesellschaft. Das Bildnis und seine Geschichte in Italien von 1300 bis heute, Berlin 1988. Martin Warnke: Hofkünstler. Zur Vorgeschichte des modernen Künstlers, Köln 1985, S. 270-307.

2 Die naturalistische Vorstellung, $\mathrm{da} ß$ Bildnisse den Menschen darstellen, sso wie er ist, wurde in der Porträtforschung vielfach problematisiert: Vgl. Gottfried Boehm: Bildnis und Individuum. Uber den Ursprung der Porträtmalerei in der italienischen Renaissance, München 1985; Lorne Campbell: Renaissance Portraits. European Portrait in the 14th, 15th and 16th Centuries, New Haven-London 1990; II ritratto e la memoria, 3 Bde., hg. von A. Gentili u.a., Rom 1993 (Biblioteca del Cinquecento; 55); Christoph Wagner. Homo absconditus Dunkelheit als Metapher im Porträt der frühen Neuzeit, in: Colloquia Academica. Akademie der Wissenschaften und der Literatur, Mainz: Akademievorträge junger Wissenschaftler, Stuttgart 1997, S. 39-95.

3 J. Burckhardt: Die Kultur der Renaissance in Italien. Ein Versuch, Stuttgart 1976, S. 284ff.

4 Erwin Panofsky: Early Netherlandish Painting. Its Origin and Character, New York 1971, Bd. 1, S. 194ff.; Kurt Bauch: Bildnisse des Jan van Eyck, in: Ders.: Studien zur Kunstgeschichte, Berlin 1967, S. 79-122; Otto Pächt: Van Eyck. Die Begrïinder der altniederländischen Malerei, hg. von M. Schmidt-Dengler, München 1989, S. 108ff.; Hans Belting; Christiane Kruse: Die Erfindung des Gemäldes, Das erste Jahrhundert der niederländischen Malerei, München 1994, S. $40 \mathrm{ff}$. 


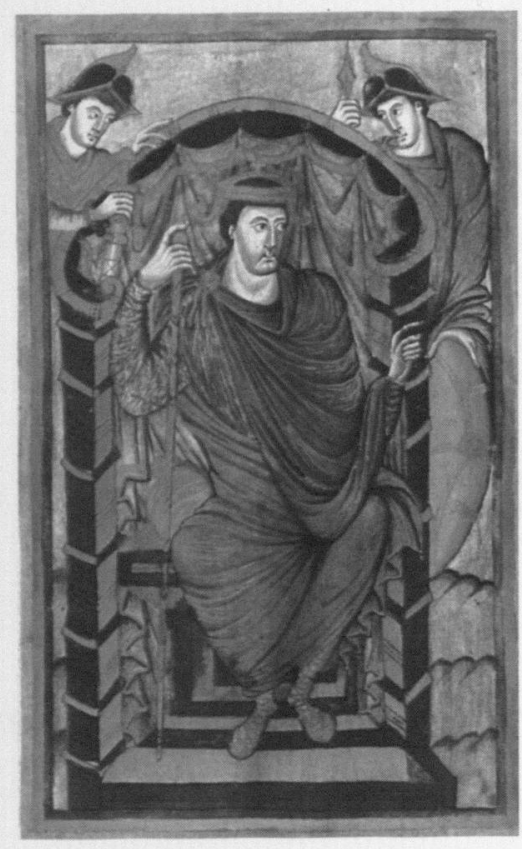

Abb. 34: Kaiser Lothar, Lothar-Evangeliar (um 850) des 15. Jahrhunderts als wichtigster kunsthistorischer Phase in der Genese des neuzeitlichen Individualbildnisses und Selbstbildnisses unbezweifelt ist, beginnt man mehr und mehr zu erkennen, daß die Genese dieser beiden Bildgattungen in einem komplexen kulturgeschichtlichen Prozeß weit ins Mittelalter zurückreicht. Schon dort werden vielfältige Aspekte und eine Fülle von grundlegenden Voraussetzungen und Errungenschaften der Bildniskunst erschlossen, die dann in der Porträtkunst des 15. Jahrhunderts auf neuer Ebene gebündelt erscheinen. Dieser Prozeß entfaltete sich zwischen den Polen anthropologischer Konstanten und kultur- bzw. kunstgeschichtlich variabler Darstellungsformen bzw. -formeln: Das was ein menschliches Gesicht in seiner individuellen Einmaligkeit ist, mußte in keiner Kultur und zu keiner Zeit den Menschen vermittelt werden, aber die Form, in der es künstlerisch veranschaulicht werden konnte, fiel über Jahrhunderte hinweg sehr unterschiedlich aus.

An diesem Prozeß sind nicht nur die Künstler, ihre künstlerischen Mittel und die Dargestellten, sondern auch die zeitgenössischen Betrachter beteiligt, denn sie sind eine wichtige Instanz, die entschied, ob ein Bildnis als Darstellung eines einzelnen Individuums oder lediglich als personifizierende Darstellung einer stilisierten Figur aufgefaßt wurde. Schließlich sind dabei auch die Berührungsflächen mit und die Abgrenzungen zu anderen benachbarten Bildgattungen zu beachten, denn nicht wenige der Aspekte der künstlerischen Gestaltung des Porträts sind nur im Vergleich mit diesen Gattungen zu bestimmen: Erst mit Blick auf die schwankenden Realitätsgrenzen zwischen den verschiedenen Darstellungsbereichen und -gattungen gerät das künstlerische Experimentierfeld genauer in den Blick, auf dem die Künstler ihre unterschiedlichen visuellen Chiffren zur Deutung des individuellen Menschen entwickelten.

Vor dem Hintergrund dieser Koordinaten ist im folgenden der historische Prozeß der Individualisierung, wie er sich im Porträt und Selbstporträt spiegelt, in exemplarischen Fallstudien zu verfolgen. Dabei ist bei der Kernfrage einer Problemgeschichte der Genese des frühneuzeitlichen Porträts anzusetzen, der Frage nach den visuellen Zeichen, Mitteln und künstlerischen Maßnahmen, die dem Betrachter vermitteln, daß es sich in einem künstlerischen Werk um ein Bildnis eines individuellen Menschen handelt und nicht um die fiktive Darstellung eines Heiligen, einer historischen oder mythologischen Gestalt. Was sind die künstlerischen Möglichkeiten zur Darstellung eines individuellen Menschen, die sich die Künstler nach dem Abreißen der bildlichen Traditionen der antiken Bildnisse unter dem ikonoklastischen Druck des frühen Christentums nach und nach erschlossen? Auch wenn die Künstler dabei von Vorbildern der antiken Bildniskunst wichtige Anregungen aufnehmen konnten ${ }^{5}$, ist der Prozeß der Individualisierung in der Genese des frühneuzeitlichen Bildnisses ein künstlerischer und geistesgeschichtlicher Prozeß sui generis, der in grundlegenden Bereichen neue Möglichkeiten der Menschendarstellung erschließt. 


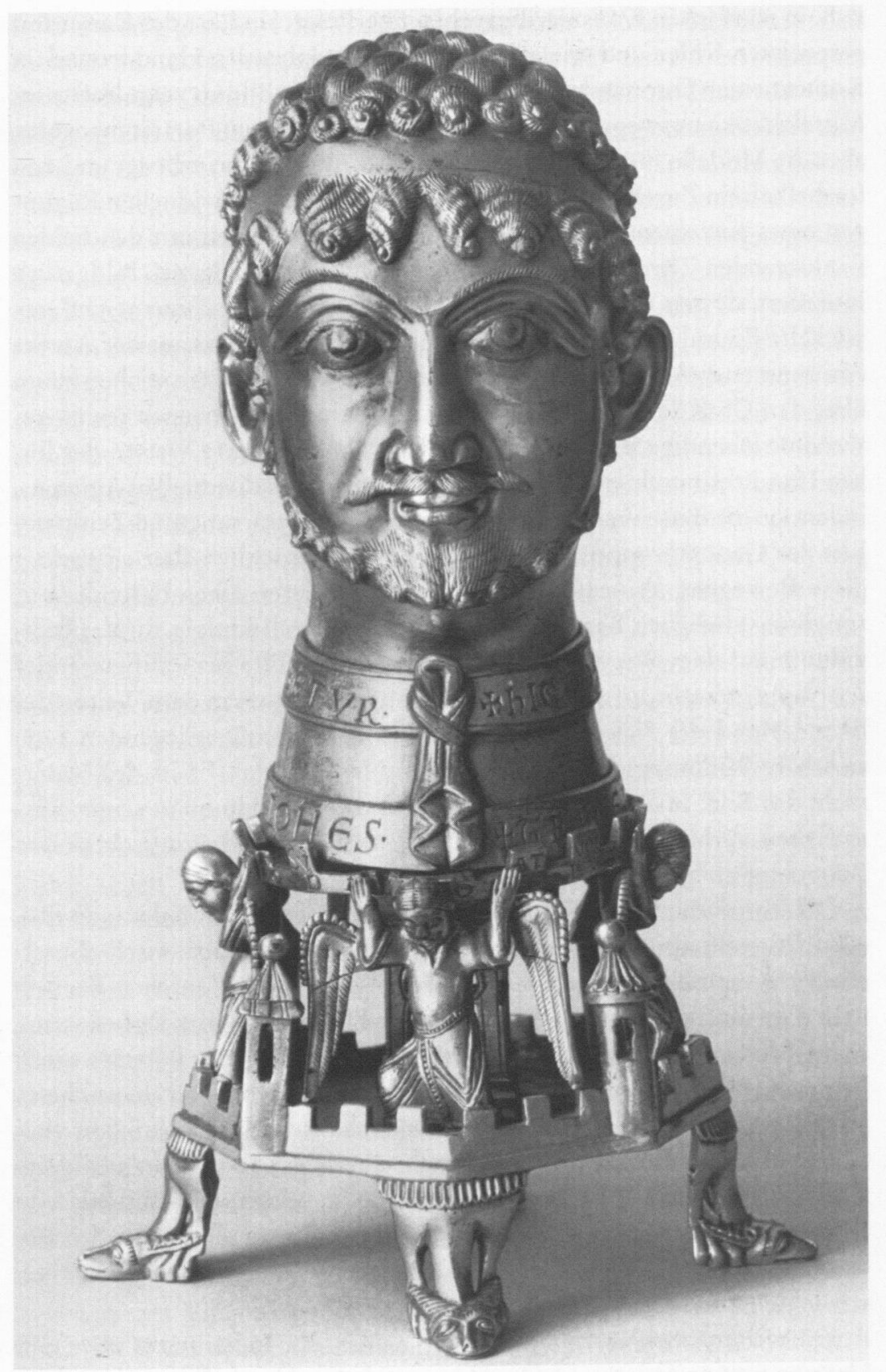

\section{Das Individuum in der Regie personifizierender Umschreibungen}

Die Bedeutung und Präsenz antiker Bildnistraditionen bildet für die historische Genese des Bildnisses schon weit vor der rinascità des 15. und 16. Jahrhunderts ein wichtiges Ferment, wie z. B. in dem Herrscherbildnis Kaiser Lothars aus dem Lothar-Evangeliar von 849-851 zu sehen ist ${ }^{6}$ (Abb. 34): Ganz im Typus eines spätantiken Herrscherbildes, wie sie
Abb. 35: Bildnis Kaiser Friedrich

Barbarossas (1155-1160)
6 Lothar-Evangeliar, Paris, Bibliothèque Nationale, Lat. 266, 221 Blatt, 250 × $322 \mathrm{~mm}$. Das Bildnis Kaiser Lothars befindet sich auf fol. IV. Vgl. Florentine Mütherich, Joachim E. Gaehde: Karolingische Buchmalerei, München 1979 (Die großen Handschriften der Welt), S. $82 \mathrm{ff}$. 


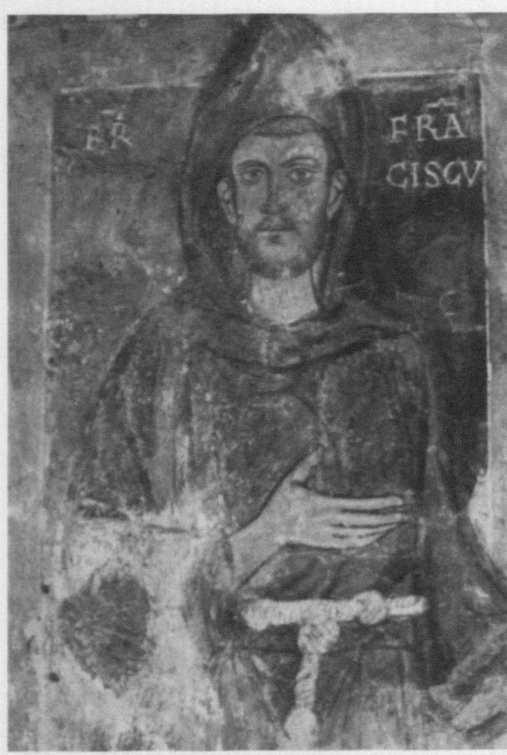

Abb.36: Anonymus, Der Hl. Franziskus (1224-28)

z. B. in römischen Konsulardiptychen überliefert sind, ist der Kaiser mit gespreizten Knien und seiner auf dem Szepter ruhenden Hand frontal im Kontext einer Thronarchitektur dargestellt. Dieses Bildnis zeigt, daß es im Mittelalter keineswegs an Ganzkörperdarstellungen im Porträt mangelte, aber die Modelle für die Darstellung des Körpers waren erborgt und von formelhaftem Zuschnitt, ohne daß sich in ihnen die individuellen Regungen eines einzelnen Menschen artikulierten. Zusammen mit den beiden flankierenden Thronwächtern ist er in ein flächenbezogenes Bildgefüge integriert, dessen strikt auskomponierte Planimetrie und nur seicht entwickelte Räumlichkeit die karolingische Umwertung der aus der Antike entnommenen Anleihen zeigt. Die stilisierten Gesichtszüge reichen kaum über den Grad der allgemeinen Typisierung hinaus. Der nach rechts gewendete lebendige Blick und das nach rechts orientierte Weisen der linken Hand vermitteln zunächst den Eindruck eines individuellen Agierens, indem sie die mittensymmetrische, heraldische Erstarrung und Zeitlosigkeit der Gesamtkomposition durchbrechen. Tatsächlich aber entspringt diese Bewegung keinem selbstbestimmten Agieren eines Individuums, sondern ist lediglich Bestandteil einer geschickten Bildregie, die das Individuum auf dem Wege der Umschreibung mit Hilfe personifizierender Attribute indirekt aufweist: Die Bewegung kulminiert in dem Weisen der linken Hand des Kaisers, die auf das auf der gegenüberliegenden Seite sichtbare Widmungsgedicht mit seinem Namen zeigt. Es ist der Name, nicht das Bild, in dem die stilisierte Figur das Individuum in seiner Einmaligkeit verbürgt, und für dessen Seelenheil die Widmungsschrift den Betrachter zu beten empfiehlt.

Die Porträtminiatur zeigt Kaiser Lothar letztlich nicht in der individuellen Darstellung eines Menschen, sondern in dem künstlerisch abgesicherten Anspruch auf Unverwechselbarkeit desjenigen Menschen, der sich über die Stiftung des Evangeliars und diese Darstellung eine Verbesserung seines Seelenheils erhoffte. Diese elementare Funktion des Porträts, einen Heilsanspruch eines einzelnen Menschen zu legitimieren und abzusichern, ist mit unterschiedlichen Gewichtungen noch bis ins 16. Jahrhundert vielfach greifbar, wenn auch mehr und mehr überlagert von anderen Bildnisfunktionen: So hat etwa noch Pinturicchio in seinem Selbstbildnis von 1501 in einem benachbart dargestellten aufgeschlagenen Buch für den Betrachter die Hoffnung notiert, daß Gott den hier dargestellten Menschen erleuchten und seine Hand schützen möge (Abb. 48).

Ein weiteres Schlüsselwerk für die Kunst, ein Individuum über den Umweg personifizierender Attribute und die Abwandlung abstrakter Formstereotypen zu umschreiben, ist die berühmte Effigie Friedrich Barbarossas (Abb. 35), die der Kaiser um 1160 seinem Taufpaten Otto von Cappenberg zugeeignet hat ${ }^{7}$. Ausdrücklich hebt der Beschenkte in seinem Testament hervor, daß der vergoldete Bildniskopf aus Bronze »nach dem Bild des Kaisers geformt « (ad imperatoris formatum effigiem) sei ${ }^{8}$. Dennoch bleibt unübersehbar, daß Kopf und Gesicht in ihrer stilisierten Formensprache bewußt in Anlehnung an antike Imperatorenbüsten gestaltet und obendrein die individuellen Züge eines einzelnen Menschen nur in den engen Grenzen eines vorgegebenen zeittypischen Form- und Motivrepertoirs, wie es in verwandten Variationen auch in anderen Kopfdarstellungen der Zeit zu finden ist ${ }^{9}$, ausgestaltet wurden. 
Wie wenig gesichert der Gattungsstatus einer solchen Bildnisbüste als Porträt im 12. Jahrhundert war, zeigt auch ein alsbald erfolgter eigentümlicher Gattungs- und Funktionstransfer: Schon Otto von Cappenberg ließ die Büste, wie die Inschrift auf dem ergänzten Sockel ausweist, in ein Kopfreliquiar Johannes des Evangelisten verwandeln, das als ritueller Gegenstand in engstem Zusammenhang mit der Taufschale Kaiser Friedrich Barbarossas stand ${ }^{10}$. Eine der Pointen dieses Vorgangs liegt darin, daß sich die hierin artikulierende Heilserwartung nicht mehr auf den Dargestellten, wie z. B. im Bildnis Kaiser Lothars (Abb. 34), sondern auf den Stifter des Reliquiars, also Otto von Cappenberg, bezog ${ }^{11}$. Diese - einem neuzeitlichen Verständnis von Individualität fremde - Rückverwandlung eines Bildnisses in einen überindividuellen rituellen Gegenstand ist für das geistesgeschichtliche Stadium und den Stand des historischen Prozesses der Individualisierung in dieser Zeit höchst signifikant. Die Inschriften der zugehörigen Taufschale belegen ${ }^{12}$, daß man die Aufhebung des Individuellen in der höheren Ebene einer göttlichen Ordnung bewußt reflektiert hat: Während im äußeren Kreis geschrieben steht »Du, den das Wasser von außen reinigt, sei des innern Menschen eingedenk, damit du werdest, was du nicht bist, wasche ab und reinige, was du bist « ${ }^{13}$, ist im inneren zu lesen: »Friedrich, Kaiser und Mehrer des Reiches, hat diese Geschenke seinem Paten Otto überreicht, jener weihte sie Gott « ${ }^{14}$. In beide Zeilen ist der Aufstieg vom Individuellen zu Gott auf unterschiedliche Weise formuliert.

Mit Blick auf die historisch benachbarten höchst stereotypen spätbyzantinischen Memorialbildnisse hat Hans Belting darauf hingewiesen, $\mathrm{daß}$ man »nur die Beschreibungen von Porträts in spätbyzantinischen Quellen nachzulesen [braucht], um sich davon zu überzeugen, daß der Betrachter daran gewöhnt war, in ihnen das genaue Ebenbild des Modells wiederzuerkennen ${ }^{15}$. Freilich darf dabei nicht übersehen werden, daß diese Quellen zunächst die Effizienz der personifizierenden Darstellungsstrategien auf der Basis umschreibender und formelhafter Stereotypen, nicht aber einen mit visuellen Mitteln gestalteten Porträttypus im neuzeitlichen Sinne belegen.

Der Zwiespalt zwischen Individualbezug und formelhafter personifizierender Darstellung ist auch im 13. Jahrhundert durchweg zu beobachten: So schematisch etwa die berühmte Darstellung eines Löwen im Skizzenbuch von Villard de Honnecourt von ca. 1235 ausfällt, so legte der Zeichner in der seiner Darstellung beigefügten Randnotiz ausdrücklich darauf wert, daß das Tier direkt nach dem lebenden Modell gezeichnet worden sei: »Ihr sollt wissen, daß er lebend abgebildet wurde «16. Diese ästhetische Haltung läßt sich analog auf die Problematik der Bildnisdarstellung dieser Zeit übertragen. Dabei wäre es unangemessen, zu einer negativen Diagnose eines mangelnden >naturalistischen $<$ Darstellungsvermögens zu kommen, vielmehr decken die Künstler »mit Hilfe der Geometrie [...] jene höhere Wahrheit auf, die sich hinter der veränderlichen Welt der Erscheinungen verbirgt ${ }^{17}{ }^{17}$. Das Individuum bleibt hier in die Vorstellung einer übergeordneten göttlichen Ordnung des Kosmos und der Welt eingebunden und in dieser aufgehoben. Zugleich aber beginnt man im 13. Jahrhundert auch den künstlerischen Eigenwert der Darstellungsweise selbst verstärkt zu reflektieren, etwa wenn Villard de

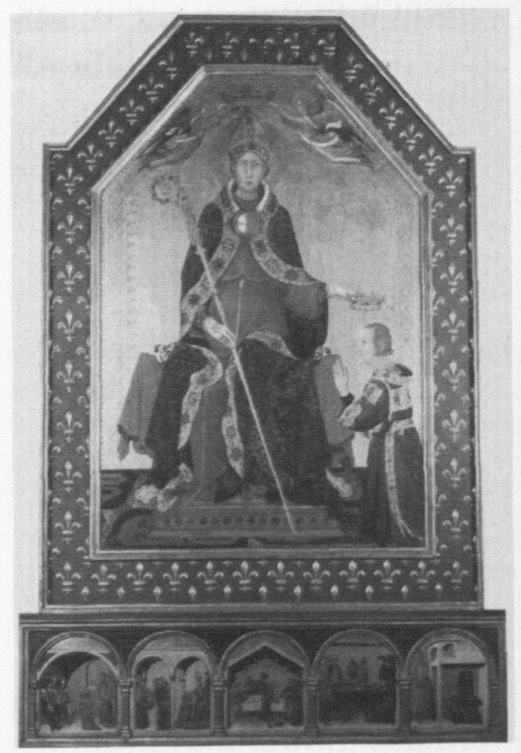

Abb. 37: Simone Martini, $H l$. Ludwig von Toulouse (1317)

10 Abb. bei A. Legner: Romanische Kunst in Deutschland, Abb. 454, S. 193, vgl. S. 78.

11 Nimm, Seher der Offenbarung, das dir gegebene Geschenk als willkommen an und eile fromm durch Fürbitte dem Geber Otto zur Hilfe / APOCALISTA DATUM TIBI MU(NUS) SUS(CIPE GR)ATUM (E)T P(I)US OTTONI SUCCURRE PRECANDO DATORI (zitiert nach A. Legner: Romanische Kunst in Deutschland, S. 77f.).

12 Büste und Taufschale gehörten eng zusammen, auch wenn in der jüngeren Forschung erwiesen wurde, daß die Büste nicht auf der Taufschale stand (A. Legner: Romanische Kunst in Deutschland, S. 78)

13 UEM LAVAT UNDA FORIS HOMINIS MEMOR INTERIORIS UT SIS Q(U)OD N(ON) ES ABLUE T(ER)GE Q(U)OD ES (zitiert nach A. Legner: Romanische Kunst in Deutschland, S. 193).

14 CESAR ET AUGUSTUS HEC OTTONI FRIDERICUS MUNERA PATRINO CONTULIT ILLE DEO (ebd.).

15 Hans Belting: Das illuminierte Buch in der spätbyzantinischen Gesellschaft, 1970, S. $72-$ 94, S. 83.

16 Paris, Bibliothèque Nationale, Ms. fr. 19093. Zitiert nach Götz Pochat: Geschichte der Ästhetik und Kunsttheorie. Von der Antike bis zum 19. Jahrhundert, Köln 1986, S. 167.

17 G. Pochat: Geschichte der Ästhetik und Kunsttheorie, S. 167. 
Honnecourt ausdrücklich $»$ zwischen der Auffassung des Künstlers, der einen Menschen darstellt (portrait) und der äußeren Ähnlichkeit zwischen abgebildeter Person und Bild (imago) « unterscheidet ${ }^{18}$.

\section{Die Entdeckung der Seelenregungen}

Vor allem die französische Kunst des 13. Jahrhunderts erschließt im weiteren mit ihrem ausgeprägten Naturinteresse der künstlerischen Darstellung des Menschen ein neues Spektrum menschlicher Regungen, das vom Lächeln bis zum Weinen und Schreien reichen kann, und weiterführend $\mathrm{z}$. B. auch an den unerhört lebensnahen Stifterfiguren am Westchor von Naumburg von $1250 \mathrm{zu}$ studieren ist ${ }^{19}$. Mit der Vielfalt dieser menschlichen Affekte und Ausdruckswerte werden weitere wichtige Voraussetzungen auch für die Bildnisdarstellung gefunden, ohne daß freilich ein hinter diesen Affektsignalen stehendes Individuum als solches in den Blick rückt: Hinter der typenhaften Verfestigung dieser extremen seelischen Regungen bleibt das Individuum weiterbin verborgen.

Im historischen Vorfeld der nominalistischen Neubewertung des Individuums im 13. Jahrhunderts, wie sie sich etwa in den philosophischen Schriften Withem von Ockhams abzeichnet ${ }^{20}$, ist das Bildnis des heiligen Franziskus in Subiaco (Abb. 36) ${ }^{21}$ entstanden, das als ein wichtiges geistesgeschichtliches Dokument dieser Frühgeschichte des Porträts und als Schlüsselwerk im Prozeß der Individualisierung die aktuellsten Strömungen der Porträproblematik im frühen 13. Jahrhundert spiegelt: Postum nur wenig nach dem Tod und noch vor der Kanonisierung des Heiligen 1228

18 G. Pochat: Geschichte der Ästhetik und Kunsttheorie, S. 161.

19 Moshe Barasch: Imago hominis. Studies in the language of art, New York, 1991, S. 89ff. Vgl. zu den Naumburger Figuren Otto von Sinson: Das Mittelalter II. Das Hohe Mittelalter, Berlin 1984, S. 241ff., (Propyläen Kunstgeschichte, Bd. 6).

20 L. Oeing-Hanhoff: Individuum, Individualität, in: Historisches Wörterbuch der Philosophie, hg. von J. Rittex und K. Gründer, Bd. 4, Darmstadt 1976, Sp. 300-310, 304ff.

21 Anonymus, Der Heilige Franziskus, 1224-28, Fresko, Subiaco, Sacro Speco (Capella di S. Gregorio).

22 Gerhart B. Ladner: Das älteste Bild des HI. Franziskus vor Assisi. Ein Beitrag zur mittelalterlichen Porträtikonographie, in: Festschrift Percy E. Schramm, Wiesbaden 1964, Bd. 1, S. 449-460, 453.

23 Siehe z. B. Piero di Cosimos *Bildnis einer Dame als Hl. Magdalena* (Holz 72, 4 × 53,4 $\mathrm{cm}$, Rom Galleria Nazionale) oder vergleiche Raphaels Darstellung der $\mathrm{Hl}$. Katharina von Alexandrien (Pappelholz, 71,5 × 55,7 cm, London, National Gallery, Inv. Nr. 168). Weiterführend hierzu Christoph Wagner: Farbe und Metapher. Die Entstehung einer neuzeitlichen Bildmetaphorik in der vorrömischen Malerei Raphaels, Berlin 1999, S. $357 \mathrm{ff}$. gemalt, stellt es den heiligen Franziskus vor einem flächigen Hintergrund mit einer ungewöhnlich weitreichenden physiognomisch-mimischen Differenzierung, einem auf den Betrachter gerichteten Blick und einer sprechenden Handgeste dar. Besonders die von Asymmetrien getragenen physiognomischen Züge des Gesichts besitzen einen neuartig frischen, weitgehend vom Schematismus stilisierter stereotyper Formeln befreiten seelischen Ausdruck. Das Entstehungsdatum dieses Bildnisses ist für seine gattungsgeschichtliche Bewertung von entscheidender Bedeutung, denn es dokumentiert, daß dieses >Erinnerungsbild historisch zunächst nicht als Heiligenbildnis konzipiert war: $» E s$ ist bemerkenswert, daß, wie es scheint, das erste Bildnis eines Menschen san sich ein Bildnis des großen Heiligen von Assisi ist, der wie kein anderer Nachahmer und Ebenbild Christi sein wollte. Dieses Bildnis von Subiaco trägt die Signatur jener neuen natürlichidealen Lebendigkeit, die schon am Anfang des 12. Jahrhunderts anhob und wohl mit einer neuen Auffassung der Ebenbildlichkeit des Menschen mit Gott zusammenhängt. ${ }^{22}$ In der Einschätzung, daß hier »ein großer Mensch um seiner selbst Willen $*$ dargestellt sei, werden freilich die rhetorischen und propagandistischen Implikationen einer solchen Darstellung des Franziskanischen Ordensgründers unterschätzt, die im Vorgriff auf eine absehbare Kanonisierung gewisse Charakterzüge, wie die Natürlichkeit und Milde bewußt hervorhoben. Mithin steht dieses Bildnis auch am Anfang eines neuen Typus eines dem Porträt benachbarten Heiligenbildnisses, wie ihn die Künstler bis ins 16. Jahrhundert hinein umfassend weiter künstlerisch erkundet haben ${ }^{23}$. 


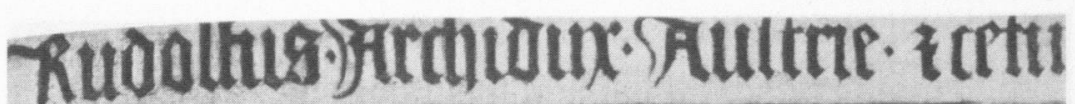

Abb. 38: Anonymus, Bildnis Herzog

Rudolf IV. von Österreich (um 1365)

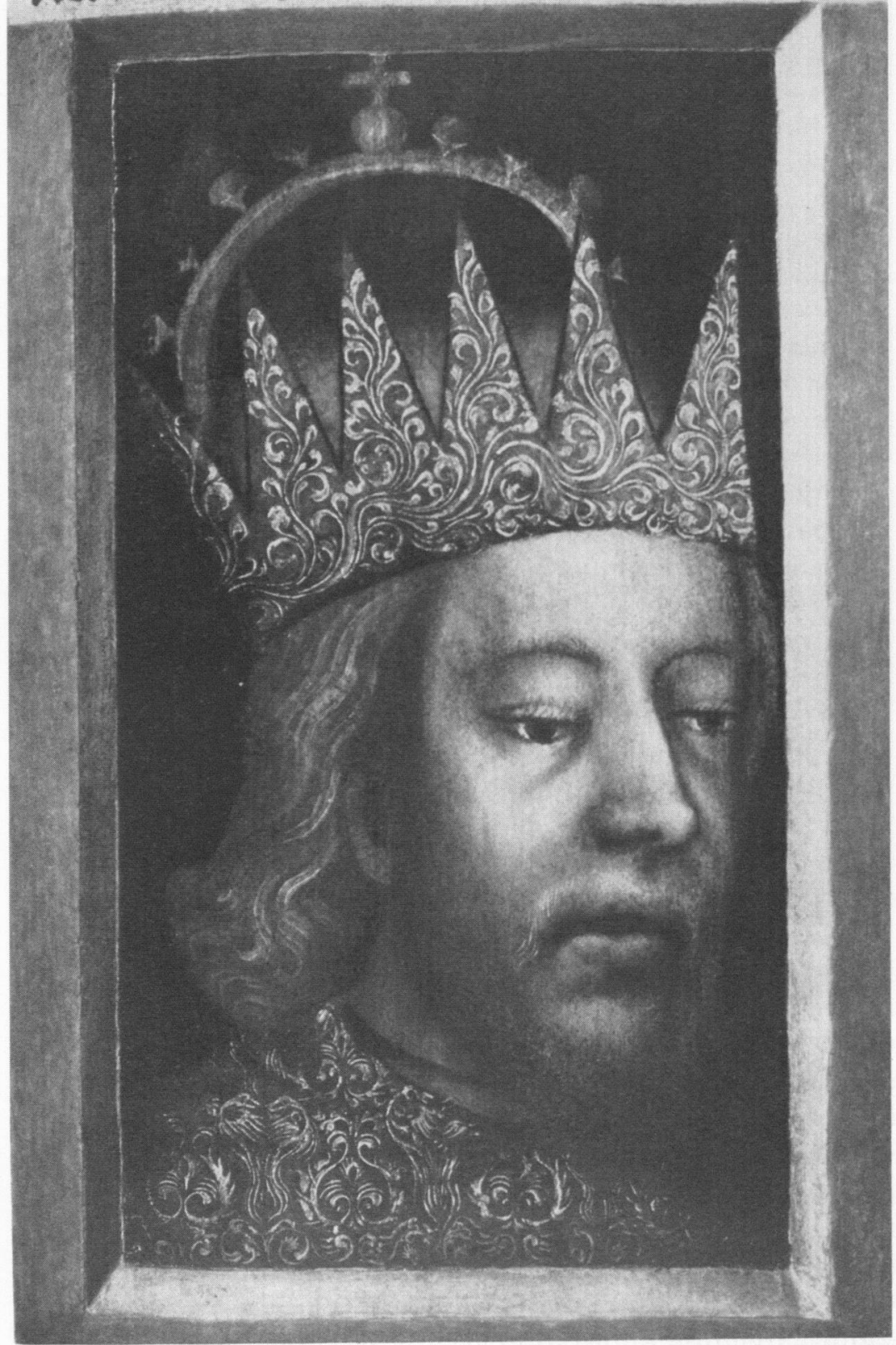

Dieses symbiotische Verhältnis zwischen Porträt und Heiligenbildnis ist für die Frühphase des Bildnisses bezeichnend, und es ist über die gesamte Zeit der Genese des frühneuzeitlichen Porträts von einer eigentümlichen historischen Dynamik beider Gattungen zueinander bestimmt: Während das Porträt in einer Zeit, in der die Darstellung eines Individuums geistesund gattungsgeschichtlich noch wenig abgesichert war, gerade im Grenzbereich zum Heiligenbildnis eine besondere Legitimation und künstlerische Entfaltungsbereiche erschließen konnte, kamen umgekehrt dem Hei- 
24 Tempera auf Holz, $309 \times 188,5 \mathrm{~cm}$ (Predella 56 $\times 205 \mathrm{~cm}$ ), Neapel, Museo di Capodimonte. modalen Differenzierung der Körperlichkeit fähig waren, ist $z$. B. auch in Duccios Maestà zu studieren (vgl. Christoph Wagner: Metaphern des Sehens und der Blindheit in der Dantezeit. Beobachtungen zur Heilung des Blindgeborenen in Duccios Maestà, in: Festschrift für Christian Lenz. Von Duccio bis Beckmann, hg. von F. Billeter u. a., Frankfurt a. M., S. 15-28.

26 Martin Gosebruch: Vom Aufragen der Figuren in Dantes Dichtung und Giottos Malerei, in: Festschrift für Kurt Badt, Berlin 1961, S. 32-65.

27 Um 1320-1330, Tempera auf Holz, $178 \times 89$ $\mathrm{cm}$ (Mitteltafel), Vatikan, Pinakothek, Inv. Nr. 40120.

28 Der Stifter ist im Kontext der Darstellung des Jüngsten Gerichts auf der Eingangswand (um 1303-5, Fresko, Padua) zu sehen. ligenbildnis gerade die im Porträtbereich neu hinzugewonnenen darstellerischen Möglichkeiten im Rahmen einer wirkungsästhetischen Aktualisierung des Heiligenbildnisses im Zuge der Devotio moderna unmittelbar zugute. Ein prominentes Beispiel für diese Verbindung von Porträt und Heiligenbildnis, zugleich ein Gründungswerk des Stifterbildnisses ist Simone Martinis Darstellung des H1. Ludwig von Toulouse, der seinen Bruder Robert von Anjou krönt (Abb. 37) ${ }^{24}$. Das Werk entstand anläßlich der Kanonisierung des Hl. Ludwig von Toulouse 1317 und diente gleich mehreren politischen Motiven und Legitimationsabsichten: Die repräsentative Inszenierung des soeben heiliggesprochenen Familienmitgliedes aus dem Hause Anjou verbindet sich mit der Absicht, die weltliche Herrschaft des jüngeren Bruders, Robert von Anjou, der durch den Verzicht des Hl. Ludwig auf die weltliche Herrschaft zum König von Neapel avancierte, zu legitimieren: Kirchliche Hoheit und weltliche Herrschaft hat Simone Martini auch mit künstlerischen Mitteln anschaulich analogisiert. Während der in ein kostbares Bischofsgewand gekleidete H1. Ludwig seinen Bruder symbolisch krönt, empfängt er selbst von Engeln die Himmelskrone._Dabei hat Simone Martini zugleich auch die geistigen Sphären von Heiligenbildnis und Porträt auf subtile Weise durch die darstellerischen Mittel seiner künstlerischen Gestaltung modal unterschieden: Während er den Heiligen in die hoheitsvolle mittensymmetrische Struktur einer frontalen Ansicht entrückt - sein Blick ist nicht auf den Bruder, sondern starr geradeaus gerichtet - und die Körperlichkeit obendrein durch das flächig-ornamentale Spiel der Falten reduziert, ist Robert von Anjou auf der rechten Seite bewegungshaft im Profil ins Bildfeld eingeführt und - im Anschluß an die malerischen Errungenschaften Giottos - plastisch stärker ausmodelliert $^{25}$.

Mit Giottos bahnbrechender malerischer Darstellung des körperlichen Volumens, der plastischen Bestimmtheit und der Schwerkraft und Beweglichkeit seiner Figuren - Martin Gosebruch sprach zutreffend vom neuartigen "Aufragen $\aleph^{26}$ - hat er zugleich auch weitere grundlegende Eigenschaften zur Darstellung von Individualität erschlossen, die plastischkörperliche Abgeschlossenheit und Ganzheit der menschlichen Figur, sowie ihr Aufragen über einem räumlich bestimmten Ort innerhalb des Bildgefüges. In Verbindung mit der bis dahin erreichten mimischen Differenzierung und Regungsfähigkeit, die Giotto ebenfalls an seinen Figuren weiter verfeinerte, ist damit zweifellos ein neuer Grad an individueller Charakterisierung erreicht, auch wenn man sich nicht darüber täuschen darf, daß Giotto die Körper seiner Figuren nicht in ihrer individuellen Einmaligkeit, sondern als Typen des Plastischen aufgefaßt hat. Ebenso ist die gestische und mimisch-physiognomische Regungsfähigkeit keineswegs isoliert als Spiegel des Individuellen zu verstehen, sondern ist als Teil einer visuellen Sprache einer umfassenden rhetorischen Stilisierung unterworfen. Ein Vergleich zwischen porträtbezogenen Darstellungen - etwa die Stifterfigur Kardinal Jacopo Stefaneschi in Giottos Stefaneschi-Triptychon ${ }^{27}$ oder der Auftraggeber der Arenakapelle, Enrico Scrovegni ${ }^{28}$ - mit rein personifizierenden Darstellungen zeigt darüber hinaus, daß Giotto seine Figuren insgesamt mit neuen menschlichen Zügen begabt hat, ohne aber eigens einen porträtspezifischen Darstellungsmodus abzugrenzen oder gar ein eigenständiges Bildnis geschaffen zu haben. Die körperlichen Merkmale 


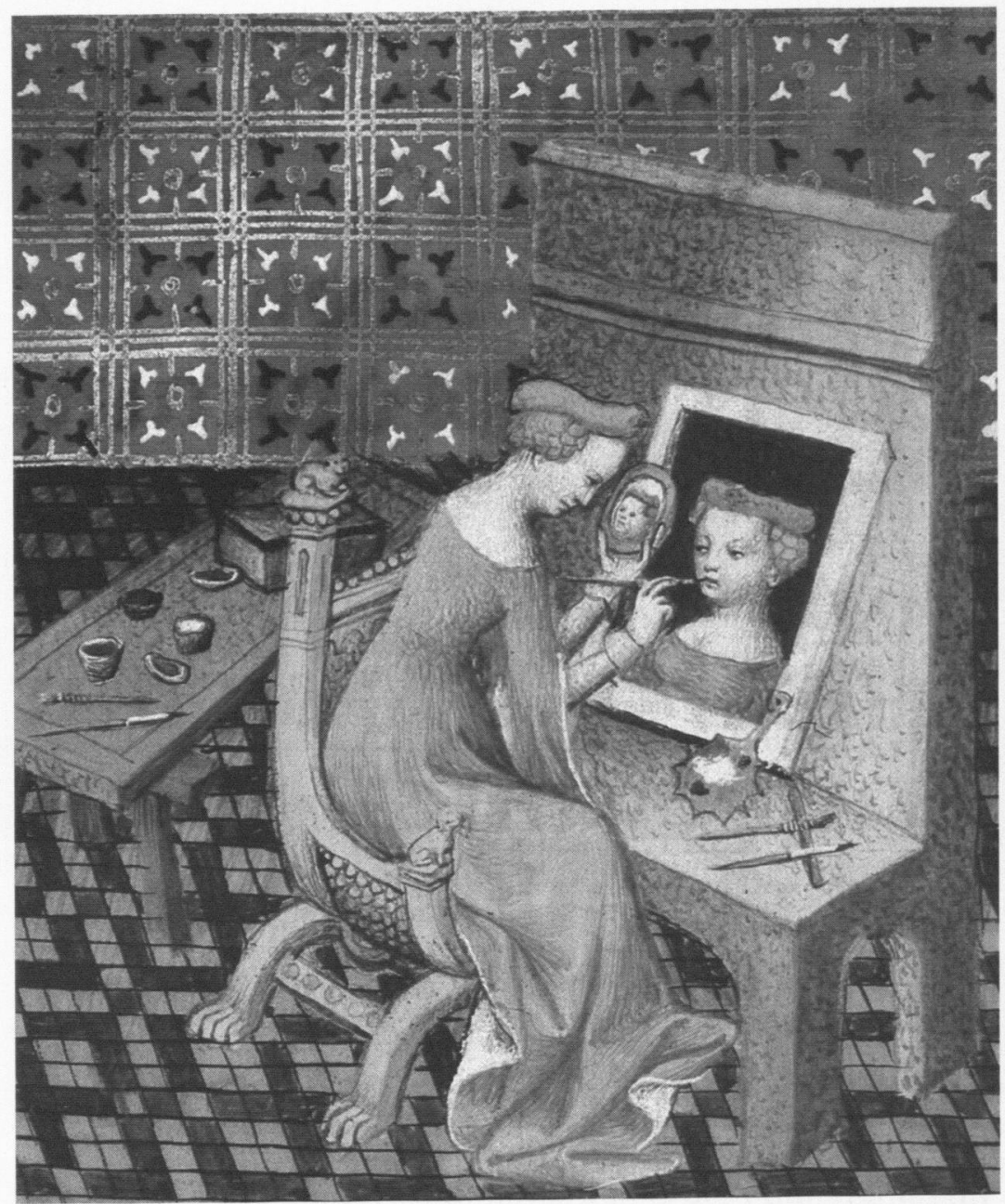

des Individuellen bleiben zu unspezifisch, um ein Porträt im neuzeitlichen Sinne entstehen zu lassen. An diesem Punkt der Geschichte der Malerei wird Individualität - entgegen der verbreiteten Rede von Giotto als Gründungsfigur einer neuzeitlichen Darstellung des Menschen ${ }^{29}$ - letztlich noch nicht im umfassenden Sinne über die plastische Erscheinung der Außenseite des Körpers erschlossen.

\section{Das Helldunkel als Erscheinungsaura und Ort des Individuums}

Wie leicht man die Legitimationsstrategien, wie sie in Simone Martinis Heiligenbildnis erkennbar wurden, im weiteren historischen Verlauf auch in den Bereich des selbständigen Bildnisses zu übertragen wußte und wie sehr diese zugleich die Autonomisierung der Gattung unterstützten, dokumentiert das ein halbes Jahrhundert nach diesem entstandene Bildnis Herzog Rudolf IV. von Österreich (Abb. 38$)^{30}$, das in seinen künstlerischen Errungenschaften eine wichtige Etappe in der Geschichte der Porträtdarstellungen zeigt: Das von anonymer Hand gemalte Bildnis ist erst kurz nach
Abb. 39: Die Malerin Marcia, aus: Giovanni Boccaccio, Des femmes nobles et renommées (1402)
29 Vgl. z. B. Harald Keller: Die Entstehung des Bildnisses am Ende des Hochmittelalters, in: Römisches Jahrbuch für Kunstgeschichte III, (1939), S. 229-356.

30 Um 1365, Pergament über Tannenholz, 48,5 x $31 \mathrm{~cm}$ (mit Rahmen), Wien, Dom- und Diözesanmuseum. 
31 Karl Oettinger: Wiener Hofmaler um $1360-$ 80. Zur Entstehung des ersten deutschen Porträts, in: Zeitschrift des Deutschen Vereins für Kunstwissenschaft, N. F. 5 (1952), S. 137-154. Hermann Fillitz: Zum Porträt Rudolfs IV. von Osterreich, in: F. Deuchler $(\mathrm{Hg}$.), Von Angesicht zu Angesicht. Porträtstudien. Michael Stettler zum 70. Geburtstag, Bern 1983, S. 99-103, 99; Johann-Christian Klamt: Herzog Rudolf IV. von Österreich, in: Otto von Simson: Das Mittelalter II, S. 280; M. Warnke: Hofkünstler, S. 270.

32 K. Oettinger: Wiener Hofmaler um 1360-80, S. $137 f f$.

33 H. Fillitz: Zum Porträt Rudolfs IV. von Österreich, S. 99.

34 Vgl. J-Ch. Klamt: Herzog Rudolf IV. von Österreich, S. 280.

35 G. Boehm: Bildnis und Individuum, S. 146.

36 H. Fillitz: Zum Porträt Rudolfs IV. von Osterreich, S. 99.

37 Ernst Strauss: Zu den Anfängen des Helldunkels, in: Ders., Koloritgeschichtliche Untersuchungen zur Malerei seit Giotto und andere Studien, hg. von Lorenz Dittmann, München-Berlin 1983 (Kunstwissenschaftliche Studien; 47), S. 47ff.; Lorenz Dittmann: Farbgestaltung und Farbtheorie in der abendländischen Malerei. Eine Einführung, Darmstadt 1987, S. 24ff.; Andreas Prater: Licht und Farbe bei Caravaggio. Studien zur Ästhetik und Ykonologie des Helldunkels, Stuttgart 1992, S. 72f.; Christoph Wagner: Farbe und Thema - Eine Wende in der Koloritforschung der 1990er Jahre? Ein Forschungsbericht, in: Zeitschrift für Ästhetik und allgemeine Kunstwissenschaf, Bd. XLII/2 (1997), S. 181249, S. $235 \mathrm{ff}$ dem Tod des Herzogs 1365, vermutlich im Auftrag des Bruders Albrecht III., entstanden und war über Rudolphs Grab im Stephansdom aufgestellt. Nicht selten wird es als $»$ das älteste bekannte selbständige Bildnis der deutschen Kunst $\ll$ bewertet ${ }^{31}$. Die Pointe der auf dem Steinrahmen notierten Inschrift $»$ Rudolfus Archidux Austriae et ceteri« und der ikonographischen Ausstaffierung mit dem Erzherzogshut - »mit Zackenkranz, Bügel und Kreuz der Kaiserkrone bedenklich angenähert $\star^{32}$ - liegt darin, daß diese gar kein historisches Faktum, sondern nur das über den Tod hinaus vorgetragene Postulat auf die Würde des Erzherzogs $\aleph^{33}$ inszeniert, dessen gefälschte urkundliche Grundlage schon längst - und zwar von Petrarca - aufgedeckt worden war ${ }^{34}$. Im Gründungsbereich der Gattungsgeschichte des autonomen Bildnisses steht folglich ein Porträt, das von der Legitimationsabsicht eines historisch unbegründeten sozialen Anspruchs getragen ist. Mit Blick auf diesen Aspekt und die Tatsache, daß damit nicht ein Individuum ausschließlich um seiner selbst willen gezeigt ist, hat man den Rang dieses Porträts als autonomes Individualbildnis eingeschränkt ${ }^{35}$ und hat es retrospektiv in die - u. a. bis zum Porträtkopf Barbarossas (Abb. 2) zurückreichende - Tradition des mittelalterlichen Herrscherbildnisses eingeordnet ${ }^{36}$.

Dabei wird vor allem der Rang der neuartigen visuellen Inszenierung dieses Bildnisses in der Geschichte des Individualporträts unterschätzt: Nicht weniger wichtig als die Tatsache, daß der Porträtkopf des Dargestellten hier als selbständiges und formatfüllendes Motiv in einem - durch einen Fensterrahmen umgrenzten - Bild erscheint und im Dreiviertelprofil ein neues $\mathrm{Maß}$ an individueller physiognomischer Charakterisierung aufweist, ist vor allem die neue Einbindung der Darstellung in ein übergreifendes Helldunkel. Das in seinen Anfängen in der böhmischen Malerei des 14. Jahrhunderts greifbare Helldunkel als grundlegende Gestaltungskategorie der neuzeitlichen Malere ${ }^{37}$ ist hier zum ersten Mal im Individualporträt zu sehen, woraus sich unmittelbar auch neue Voraussetzungen und Perspektiven für die existentielle Deutung des Individuums ergaben: Der dargestellte Mensch ist nicht mehr reduziert auf eine gleichsam atmosphärelose, ort- und zeitlose Beschreibung der plastisch ausmodellierten Faktizität des Körperlichen, sondern er wird umfangen von einem Helldunkel, das das Individuum für den Betrachter auf neue Weise unter den räumlichen und zeitlichen Bedingungen des Erscheinens, eingebunden in die Polarität von Präsenz und Absenz, von Sichtbarkeit und Unsichtbarkeit zeigt: In dem Augenblick, in dem die Individualität unter den Bedingungen einer Helldunkelerscheinung sichtbar wird, ist zugleich auch das Unsichtbare an dem dargestellten Menschen stets mit thematisiert. Damit ist - schon auf dem Boden des höfischen Porträts - eine perspektivenreiche neue visuelle Deutung des Menschen eingeführt, mit der sich die europäische Porträtmalerei über Jahrhunderte hinweg vielgestaltig auseinandersetzen wird. Man mag dabei mit Blick auf dieses erste Werk zugestehen, daß der Dargestellte sich nicht direkt an den Betrachter wendet und daß der anonyme Künstler dieses Bildnisses die Helldunkelaura noch nicht vollkommen als Erscheinungsaura eines individuellen Menschen zu deuten wußte. Freilich kommt in diesem Porträt schon viel von der komplexen charakterlichen Disposition eines einzelnen Menschen im verzeitlichten Modus des Helldunkels zur Erscheinung. 


\section{Die Anfänge des Selbstbildnisses}

Die bildkünstlerische Erkundung des individuellen Menschen in seiner komplexen charakterlich-körperlichen Disposition nimmt im 15. Jahrhundert als Bildthema einen neuen Rang und qualitativ neue Züge an, der Prozeß der Individualisierung tritt in eine neue Phase. Symptomatisch hierfür ist nicht zuletzt auch die verstärkte Selbsterkundung der Maler im Selbstporträt. Die erste neuzeitliche Darstellung, die die Entstehung eines Selbstporträts thematisiert, ist in einer Miniatur aus der französischen Übersetzung der Schrift »De mulieribus claris « Giovanni Boccaccios 1402 überliefert ${ }^{38}$ (Abb. 39), die die Malerin Marcia bei der Herstellung ihres Selbstporträts mit Hilfe eines Spiegels zeigt: Während sie mit ihrer Linken einen Spiegel hält, in dem sie ihr Antlitz studiert, überträgt sie mit dem Pinsel in ihrer Rechten die Züge in das rechteckige Format eines eigenständigen Porträtbildes, das von weiteren Malutensilien umgeben ist. Hervorzuheben ist dabei, daß sich dieses für die neuzeitliche Malerei neue Bildthema nicht etwa auf die Darstellung einer zeitgenössischen Künstlerin, sondern auf einen von Boccaccio aufgenommenen Antikenbericht bei Plinius bezieht ${ }^{39}$. Noch überraschender ist, daß in dieser Miniatur ein Selbstporträt als Bild im Bild dargestellt ist, noch bevor überhaupt die Gattung des autonomen Selbstporträts in überlieferten Werken dokumentiert ist. Selbstbildnisse waren bis dahin allenfalls über Assistenzfiguren in mehrfigurige Darstellungen integriert, wie etwa in Giottos Fresken im Palazzo del Podestà, über die Filippo Villani 1395 berichtete $^{40}$, oder in Agnolo Gaddis Darstellung des "Einzugs des Heraklius in Jerusalem « in der Chorkapelle von S. Croce in Florenz ${ }^{41}$.

Mit Beginn des 15. Jahrhunderts erscheinen Selbstbildnisse auch mit der Funktion gleichsam gemalter Signaturen in der Peripherie übergeordneter Werke: Diese zweite Vorform des autonomen Selbstporträts ist zum ersten Mal um 1400 in dem Selbstbildnis Cola Petrucciolis im Chorbereich von San Domenico in Perugia zu sehen (Abb. 40) ${ }^{42}$. Hinter einem vierpaßförmigen Durchblick, der in die Rahmung einer Verkündigungsdarstellung eingelassen ist, hat sich Cola Petruccioli in leuchtend blauer Malermontur und in strenger Frontalität so dargestellt, daß die erzählerische Suggestion entsteht, daß er gerade bei der Arbeit seinen Pinsel in einem Napf mit rotem Pigment abstreift: Es ist gleichsam die Farbe des lebendigen Fleisches, in die Cola seinen Pinsel taucht und damit dem Betrachter zeigt, mit welchen Mitteln er sein Selbstbildnis und die umgebenden Szenen anschaulich verlebendigt hat. Ein weiteres Detail dieses Selbstbildnisses bedarf genauerer Betrachtung, denn es ist aufschlußreich für den Stand der darstellerischen Entwicklung: Nur oberflächlich gesehen ist der Blick Colas direkt auf den Betrachter gerichtet. Eine weiterführende Analyse zeigt, daß seine Augen das Schauen eher fingieren, als tatsächlich in fokussierendem Blick den Betrachter zu fixieren. Auch von dem Inneren des Dargestellten geben sie nichts preis.

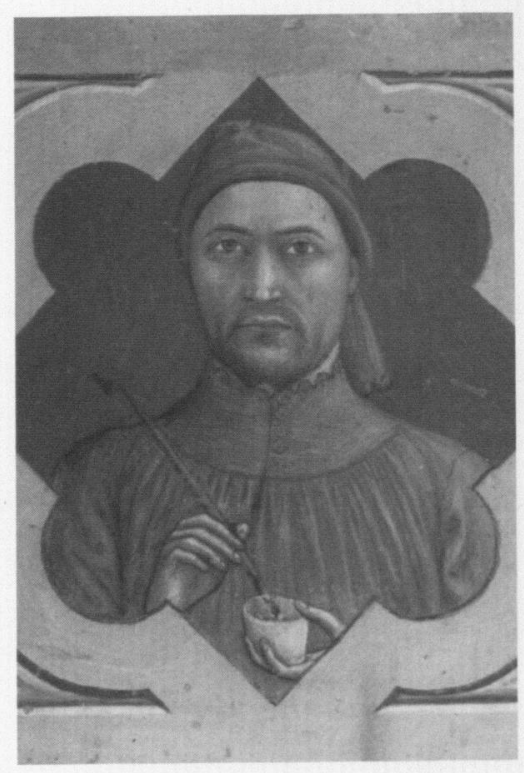

Abb. 40: Cola Petruccioli, Selbst-

bildnis (um 1400)

38 Diese prächtig illustrierte Handschrift befand sich im Besitz Philipp des Kühnen. Bibliothèque Nationale, Paris, Ms fr. 12420. Vgl. C. Bozzolo, Manuscrits des traductions françaises d'œuvres de Boccace, XVe siècle, Padua 1973, S. 91ff. und Hermann Ulrich Asemissen; Gunter Schweikhart: Malerei als Thema der Malerei, Berlin 1994 (Acta humaniora), S. 57.

39 Plinius beschreibt, wie die berühmte antike Porträtistin Iaia mit Hilfe von Spiegeln ihr eigenes Bildnis anfertigte (C. Plinius Secundus d. Ä.: Naturkunde. Buch 35: Farben, Malerei, Plastik / C. Plinii Secundi: Naturalis historiae Liber XXXV, Lateinisch - deutsch, hg. und Übersetzt von R. König in Zusammenarbeit mit G. Winkler, Darmstadt 1997, S. 112f., \$ 147; vgl. H. U. Asemissen; G. Schweikhart: Malerei als Thema der Malerei, a. a. O., 59

40 Vgl. Michael Baxandall: Giotto and the orators. Humanist observers of painting in Italy and the discovery of pictorial composition 1350-1450, Oxford 1971, S. 66ff., $146 f f$.

41 Siehe hierzu Giorgio Vasari: Le vite de' più eccelenti pittori, scultori ed architettori... (1550/1568), hg. von G. Milanesi, Nachdruck der Ausgabe Florenz 1906, hg. von P. Barocchi, Florenz 1981, Bd. 1, S. 646.

42 Siehe zu Werk und Biographie: La pittura in Italia. Il Duecento e il Trecento, Bd. 2, Mailand 1985, S. 649f. 
Abb. 41: Jan van Eyck, Jan de Leeuw

(1436)

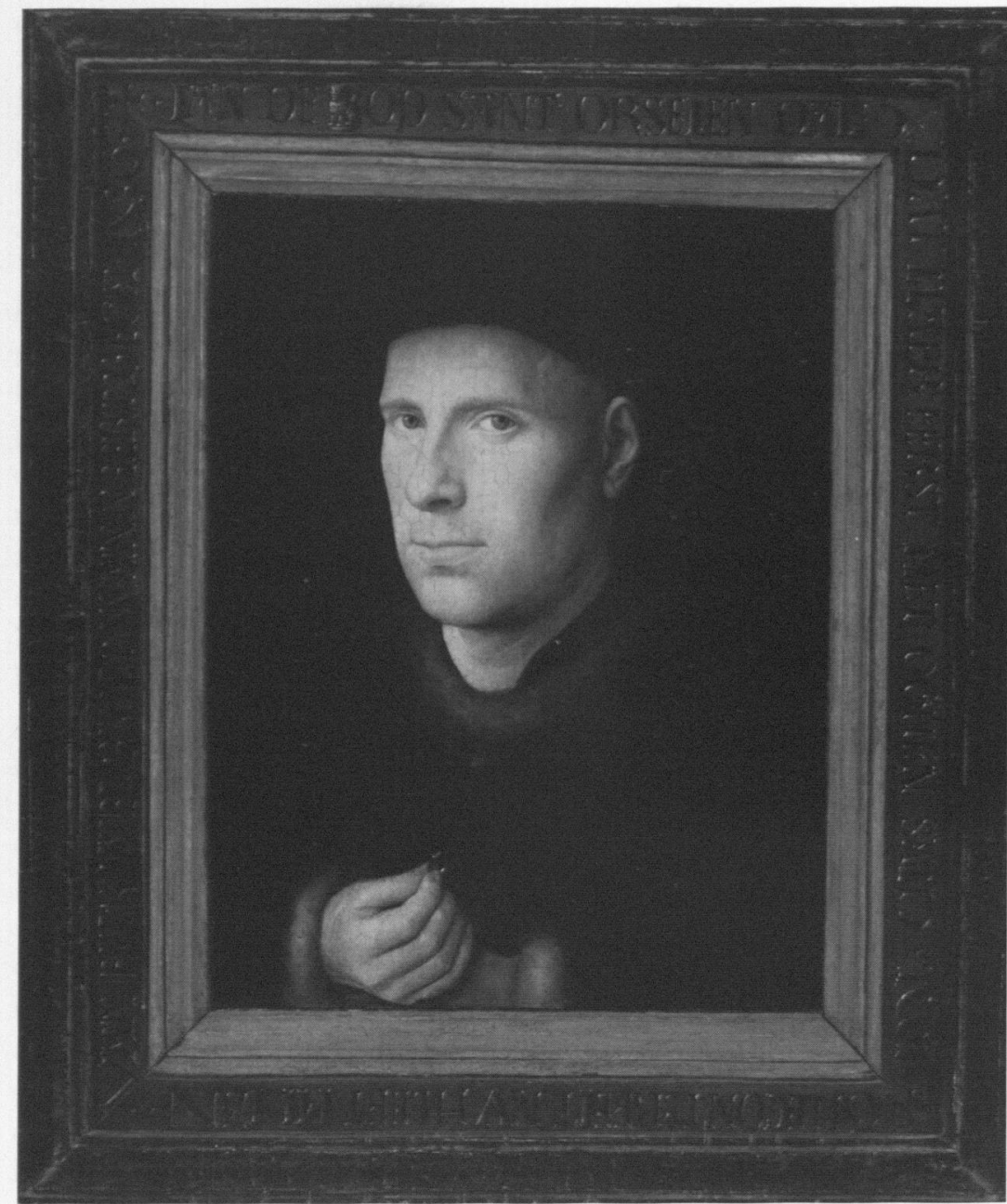

43 Jan Bialostocki: The eye and the window. Realism and Symbolism of Light-Reflections in the Art of Albrecht Dürer and His Predecessors, in: Festschrift für Gert van der Osten, Köln 1970, S. 159-176; H. Belting; Ch. Kruse: Die Erfindung des Gemäldes, S. 51ff. (mit Bibliographie S. 275ff.).

44 Vgl. E. Panofsky: Early Netherlandish Painting, Bd. 1, S. 194ff.; Otto Pächt: Van Eyck, S. 107ff.; Dieter Jansen: Similitudo. Untersuchungen zu den Bildnissen Jan van Eycks, Köln 1988 (Dissertationen zur Kunstgeschichte; 28); H. Belting; Ch. Kruse: Die Erfindung des Gemäldes, S. $39 \mathrm{ff}$.

\section{Das Auge als Fenster der Seele}

Ganz anders hat Jan van Eyck in der Darstellung des Menschen die Augen interpretiert, indem er die Metapher vom »Auge als Fenster der Seele « ins Zentrum einer neuartigen Erkundung der Persönlichkeit des Menschen rückte. Bisweilen hat er diese Schlüsselmetapher seiner Deutung des Menschen im Motiv eines Fensterkreuzes, das sich im Auge der Dargestellten spiegelt, in seinen Bildnissen wiedergegeben ${ }^{43}$ (vgl. Abb. 41).

In den Bildnissen Jan van Eycks erscheinen auch alle übrigen vorausgegangenen künstlerischen Errungenschaften in der Entwicklung des Porträts auf ein qualitativ neues Niveau gehoben und in Verbindung mit einer umfassenden Erkundung des Sichtbaren zu einer für die nachfolgende Malerei paradigmatischen Form des Porträts gebündelt: Daß dieser Vorgang kunsthistorisch nur wenig vermittelt - u. a. durch die charaktervoll-plastischen Porträts Robert Campins - und gleichsam ohne größere personalstilistische Entwicklung im CEuvre Jan van Eycks mit schlafwandlerischer Si- 
cherheit geschieht ${ }^{44}$, hat den Mythos von der Entstehung des neuzeitlichen Porträts im Werk Jan van Eycks begründet: »Voraussetzungslos wie Wunderwerke wirken seine Bilder ${ }^{45}$.

Schon das früheste erhaltene Porträt von der Hand Jan van Eycks, seine um 1420 entstandene Darstellung eines »Mannes mit Ring « in Bukarest, zeigt alle Aspekte seiner Bildniskunst, ebenso das mit diesem eng verwandte, 1436 datierte Bildnis des Goldschmieds Jan de Leeuw (Abb. 41) ${ }^{46}$ : Das nahsichtig studierte und mit neuem Realismus dargebotene Verosimile des Dargestellten, die perspektivisch kühn gelöste Aúfnahme der Arme und Hände als Akteure eines scheinbar freibeweglich agierenden Individuums, die Umdeutung des Bildrahmens zur Brüstung, durch die sich der Körper im Ganzen bildhaft gerahmt präsentiert, die Einbindung des Menschen in eine raum-zeitliche Helldunkelaura, aus der er in neuer Form für den Betrachter einen Erscheinungsort gewinnt, und eine neuartige seelische Charakterisierung, die dem Betrachter einen Menschen in seiner mimisch-physiognomischen Besonderheit anschaulich vor Augen stellt. Aus der umgebenden Dunkelheit, in die der Chaperon und das Gewand eingebunden sind, treten Gesicht und Hand fast ereignishaft ins Licht, gewinnen eine Präsenz, die im Blick und dem funkelnden Rubinring zwischen den Fingern des Goldschmieds kulminiert. Der Mensch und der in seinen Händen gehaltene Gegenstand scheinen sich hier wechselseitig zu kommentieren, indem sie den Beruf und Stand des Dargestellten aufweisen, ohne freilich das Individuum in einer solchen Zuordnung verschwinden zu lassen.

Zur neuen Inszenierung des Individuums gehört auch eine neue Bildregie: Durch den aus dem Bild heraus gerichteten Blick des Dargestellten macht Jan van Eyck den Betrachter auf eigentümliche Weise auch zum Betrachteten, entfaltet eine neuartige Interaktion zwischen den Realitätssphären inner- und außerhalb des Bildes, die zu seiner neuen visuellen Deutung des Menschen wesentlich hinzugehört. Gleich zweifach wird die Welt des dargestellten Individuums erweitert: nach Innen zu einem eigenen Erscheinungs- und Handlungsraum hin, nach außen im direkt auf den Betrachter gerichteten Blick ${ }^{47}$. Schon Nikolaus von Kues hat über dieses neue Phänomen der doppelten Blickbeziehung in der bildlichen Darstellung seiner Zeit, mit Blick auf ein Bildnis von der Hand Rogier van der Weydens, dessen Blick dem Betrachter zu folgen scheint, meditiert ${ }^{48}$. Zwischen diesen Realitätssphären hat Jan van Eyck den Rahmen in kunstvoll illusionistischem Spiel als vermittelnden Zwischenbereich gestaltet: Ein im Bildnis Jan de Leeuws scheinbar aus Metall gearbeitete, gemalte Inschrift akzentuiert sowohl die Zeitlichkeit des dargestellten Menschen, die des Bildes, wie - in der Transitorik der Lichtreflexe - die des Bildlichtes und der davon abhängigen Wahrnehmung. Die intellektuelle Differenziertheit dieser ästhetischen Reflexion spiegelt das Niveau einer anthropologischen Selbstreflexion, wie sie in schriftlichen Quellen dieser Zeit schwerlich zu finden ist.

Auch am Anfang der Geschichte des autonomen neuzeitlichen Selbstbildnisses steht eine Darstellung Jan van Eycks, der sogenannte »Mann mit Turban« (1433 datiert, Abb. 42), die - trotz fehlender lückenloser historischer Dokumentation - mit Recht mehrheitlich als das in den Quellen überlieferte Selbstbildnis Jan van Eycks angesprochen wird ${ }^{49}$ : Die $\times 27,5 \mathrm{~cm}$, Wien, Kunsthistorisches Museum. Abbildung des Mannes mit Ring (1420-25, Eichenholz, 22,5 x 16,6 cm, Bukarest, Rumänisches Nationalmuseum) in: $H$. Belting; Ch. Kruse: Die Erfindung des Gemäldes, 151, Abb. 40.

47 E. Panofsky: Early Netherlandish Painting, Bd. 1, S. $194 \mathrm{ff}$.

48 Nikolaus von Kues: De visione Dei / Von Gottes Sehen, in: Ders.: Philosophisch-theologische Schriften, hg. von L. Gabriel, Wien 1989, Bd. 3, S. 93-219, S. 94ff, 128ff. Vgl. H. Belting; Ch. Kruse: Die Erfindung des Gemäldes, S. $55 f f$. H. U. Asemissen; G. Schweikhart: Malerei als Thema der Malerei, S. $66 f$.

491433 , Eichenholz, $33,3 \times 25,8 \mathrm{~cm}$, London, National Gallery. Forschungsbericht bei $H$. Belting; Ch. Kruse: Die Erfindung des Gemäldes, S. 151. 


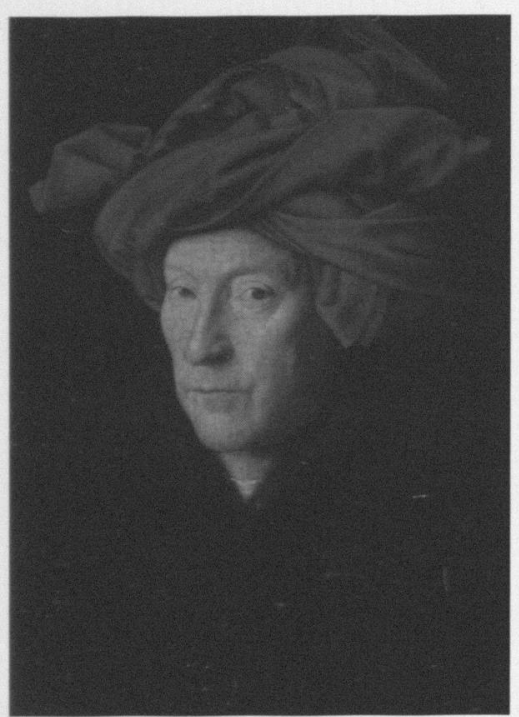

Abb. 42: Jan van Eyck, Mann mit

Turban (1433)
Darstellung stimmt in vielen Punkten mit den in Spiegelungen verborgenen Selbstbildnissen Jan van Eycks in anderen Werken überein ${ }^{50}$, entspricht als >Pendant dem Bildnis der Ehefrau Jans, Margaretha van Eyck, und trägt in der Rahmeninschrift in griechischen Lettern das Motto Jan van Eycks »als ich can«. Auch die Tatsache, daß die Inschrift nicht den Namen des Dargestellten vermerkt, sondern nur das Bild zum Betrachter sprechen läßt, »Johann de Eyck me fecit «, ist naheliegenderweise im Kontext eines Selbstbildnisses zu verstehen. Auch hier bildet der Erscheinungsort des Individuums eine alles umgebende Dunkelheit, aus der das Licht ein bis in die Einzelheiten der Bartstoppeln analysiertes Gesicht befreit. Zur Steigerung der Konzentration auf das Gesicht hat Jan van Eyck auf das Motiv der Hände verzichtet. Der prüfend skeptische Blick, der diese Sichtbarkeit - nicht ohne Vorbehalt gegenüber der eigenen Eitelkeit $^{51}$ - ins Bild gebracht hat, ist nun auf den Betrachter gerichtet. Gleich ob Jan van Eyck selbst oder spätere Betrachter auf dieses Selbstporträt blicken, ist es über die Darstellung eines einzelnen Menschen hinaus der Mensch selbst, der sich in dieser prüfenden Kreuzung der Blicke in einer neuartigen Konzentration, begegnet. Diese Erschließung des Auges als anthropologischem Schlüsselpunkt des Menschen, als Spiegel seiner Welt und als Fokus einer potentiellen Interaktion mit dem Betrachter bildet eine zentrale Errungenschaft in der Deutung des Individuums in den Bildnissen Jan van Eycks. Gleichsam programmatisch für den neuen Modus einer akribisch in der Malerei eingefangenen Sichtbarkeit, hat Jan van Eyck vielfach - prominent in der Arnolfini-Hochzeit ${ }^{52}$ - auch die Metapher des Spiegels thematisiert. Das Verosimile der Malerei ist als Spiegelbild der Wirklichkeit angetreten, das freilich nach eigenen Gesetzmäßigkeiten der Wahrnehmung funktioniert.

\section{Das Porträt als "höfisches Produkt" oder "bürgerliche Erfindung *}

Die Tatsache, daß Jan van Eyck in seinen heute überlieferten Bildnissen ausschließlich Menschen einer >bürgerlichen`Schicht aus dem Umkreis des Hofes dargestellt hat ${ }^{53}$, hat zu der Hypothese geführt, daß das selbständige Bildnis nicht am Hofe - wie z. B. Martin Warnke meinte ${ }^{5}$-, sondern als bürgerlicher Gegenentwurf und als Konkurrenzprodukt zum stilisierten Idealbildnis am Hofe entstand ${ }^{55}$. Kurt Bauch hat darüber hinaus sogar vermutet, daß die neue Bildnisform Jan van Eycks wesentliche Anregungen der künstlerischen »Sphäre der neuen Bildungsschicht « in Italien und speziell in Florenz verdanke ${ }^{56}$. In diesem Zusammenhang wird leicht übergangen, daß Jan van Eyck durchaus nicht nur als >bürgerlicher Porträtist anzusprechen ist, sondern als »varlet de chambre « am Hofe von Burgund auch als Hofporträtist arbeitete, auch wenn uns aus dieser Tätigkeit kein Werk unmittelbar überliefert ist. Kopien und Quellenberichteetwa zu Jan van Eycks Bildnis der Tochter Herzogs Philipp des Guten, Isabella, von $1429^{57}$ - zeigen aber, daß die Entwicklungen des >bürgerlichen und des shöfischen Porträts im EEuvre Jan van Eycks nicht ohne weiteres zu trennen sind. Auch ist die Tendenz zu einer >realistischeren Darstellung des Menschen schon vor Jan van Eyck im Kontext des höfi- 
schen Porträts wie z. B. in dem um 1415 entstandenen Profilbildnis Ludwig II. von Anjou aus dem Umkreis der Gebr. Limburg ${ }^{58}$ zu beobachten, ebenso die schon angesprochene wichtige visuelle Errungenschaft, das dargestellte Individuum in ein übergreifendes Helldunkel als Erscheinungsort einzubinden, wie in dem Bildnis Rudolphs IV. (Abb. 38). Gleichwohl ist ebensowenig zu leugnen, daß die Gattungsentwicklung gerade in der Auseinandersetzung der Künstler mit Porträtaufträgen aus einer $>$ bürgerlichen $<$ Schicht solch zahlreiche entscheidende Impulse empfing, daß eine Abgrenzung des Porträts als genuinem >Produkt der höfischen Kunst< unangemessen ist ${ }^{59}$. Einer genealogischen Ableitung dieser Bildnisform aus der italienischen Kunst schließlich steht die Tatsache entgegen, daß die italienischen Maler sich selbst noch ein halbes Jahrhundert lang nicht dieses Typus im autonomen Bildnis bedienten, sondern weiterhin - wie paradigmatisch im Werk von Pisanello zu sehen (vgl. Abb. 43) - im Modus von Profildarstellungen gestalteten. So scheint ein vorläufiges Fazit bis zu diesem Punkt der Gattungsentwicklung darin zu liegen, daß die Genese des neuzeitlichen Porträts nicht aus linear zu entwickelnden Kausalitäten und schon gar nicht als lineare Entwicklung oder Errungenschaft einer einzelnen Gesellschaftsschicht oder eines einzelnen Malers zu erklären ist, sondern aus einem diskontinuierlichen Prozeß hervorgegangen ist, der von der visuellen Erschließung neuer Seiten am Menschen getragen ist, aus dem die Künstler jeweils ihre Konsequenzen für ihre anthropologische Deutung des Menschen in ihren Darstellungen zogen. Auch ist hervorzuheben, daß dieser Prozeß der Individualisierung im neuzeitlichen Porträt in den Bildnissen Jan van Eycks zwar zum ersten $\mathrm{Mal}$ zu einer gattungsgeschichtlich bedeutenden paradigmatischen bildlichen Form gefunden hat, keineswegs aber damit abgeschlossen ist. Auch Jan van Eyck lieferte nur einen unter mehreren Entwürfen zur Darstellung des Menschen, und es wäre falsch, die Ästhetik des Porträts und seine geistes- und gattungsgeschichtliche Entwicklung mit den Normen und Paradigmen der van Eyckschen Porträtkunst gleichzusetzen.

\section{Der Prozeß der Individualisierung in Italien}

Dies zeigt besonders der Vergleich mit der weiteren gattungsgeschichtlichen Entwicklung des Porträts in der italienischen Kunst, die - äußerlich betrachtet - zunächst ein halbes Jahrhundert hinter der Entwicklung des Porträts in der altniederländischen Malerei hinterher zu hinken scheint, tatsächlich aber eine entscheidende weitere Etappe in der Darstellung des individuellen Menschen vorbereitet. Auch wenn Jacob Burckhardt zutreffend hervorgehoben hat, daß die Kunst des Porträts sich prinzipiell erst in Spätzeiten der Kunstgeschichte voll entfaltete ${ }^{60}$, so ist es historisch dennoch bemerkenswert und kaum erklärlich, daß die italienischen Künstler - bei ansonsten durchaus bestehendem künstlerischen Austausch - im 15. Jahrhundert offensichtlich nicht direkt an die Errungenschaften der Porträtgestaltung in der altniederländischen Malerei anschließen konnten oder wollten. Offenbar mußten sie den Prozeß der Individualisierung auf eigenen Wegen durchlaufen und eigenständig

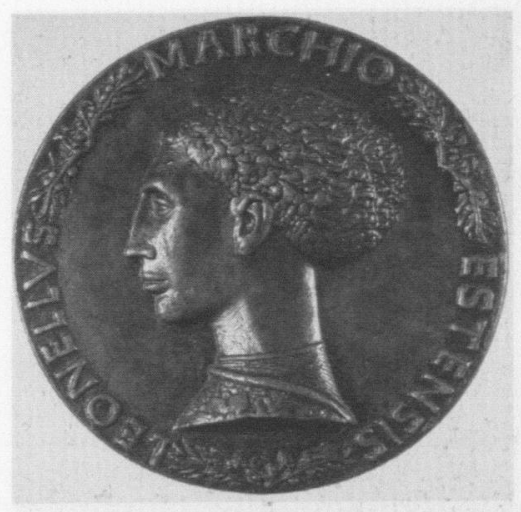

Abb. 43: Pisanello, Medaille des Leonello d'este (nach 1441)

58 Wasserfarben auf Papier, 22,2 × 17,3 cm, Paris, Bibliothèque Nationale, Cabinet des Estampes; vgl. H. Belting; Ch. Kruse: Die Erfindung des Gemäldes, S. 150.

59 M. Warnke: Hofkünstler, S.270.

60 J. Burckhardt: Beiträge zur Kunstgeschichte in Italien, S. 145f. 


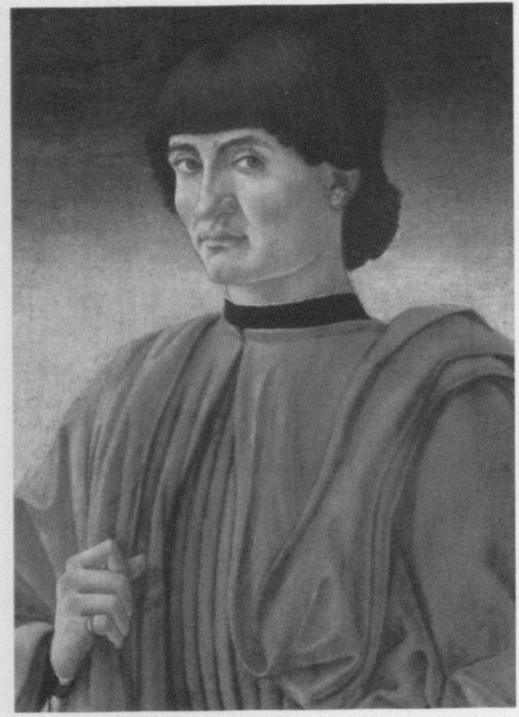

Abb. 44: Andrea del Castagno, Bildnis eines Mannes (um 1450)

61 Auf diesen wichtigen wahrnehmungsgeschichtlichen Aspekt hat Ernst Strauss (The Picture Plane and its Interpretation, in: Ders.: Koloritgeschichtliche Untersuchungen zur Malerei seit Giotto und andere Studien, S. 2735, 34f.) aufmerksam gemacht. Vgl. an Strauss anschließend auch John Pope-Henessy: The Portrait in the Renaissance. The A. W. Mellon Lectures in the Fine Arts. 1963. The National Gallery of Art, Washington, D. C., Washington 1963 (Bollingen Series XXXV, 12) S. 56.

62 Privatbesitz. Vgl.: Pisanello und Bono da Ferrara, Bernhard Degenhart und Annegrit Schmitt, München 1995, S. 208.

631441 , Holz, 29, $5 \times 18,4 \mathrm{~cm}$, Bergamo, Accademia Carrara. Vgl. auch das Bildnis der Ginevra d'Este, Holz, $43 \times 30 \mathrm{~cm}$, Paris, Louvre.

64 J. Pope-Henessy: The Portrait in the Renaissance, S. $41 \mathrm{ff}$.

$65 \mathrm{Vgl}$. G. Boehm: Bildnis und Individuum, S. 214. nach einer angemessenen visuellen Form für das Porträt suchen. Nicht einmal die in der altniederländischen Malerei so vorbildlich gelöste Verbindung von Bildformat und erweiterter Körperdarstellung wurde in die italienische Malerei direkt übernommen.

Warum es zu dieser historischen Aufspaltung in dieser wichtige Phase der Genese des neuzeitliche Porträts in verschiedenen Kunstlandschaften kam, ist nur hypothetisch zu erklären. Es könnte mit den grundsätzlich verschiedenen Ausgangspunkten und wahrnehmungsgeschichtlichen Dispositionen in der bildkünstlerischen Gestaltung in der altniederländischen und italienischen Malerei zusammenhängen: Während die altniederländischen Maler wie Jan van Eyck durch ihre an der Buchmalerei geschulte Darstellungsweise eine nahsichtige, vom Gestus des Intimen getragene Erkundung des Sichtbaren und des Raumes entwickelt hatten und diese Aspekte leicht in die Darstellung des Porträts mit seinem nahsichtigen Sichtbarkeitsmodus übertragen konnten, waren die italienischen Maler am Paradigma der Freskomalerei an einer viel weniger detailbezogenen, stärker auf die fernsichtige Flächenwirkung hin orientierten Darstellungsweise interessiert ${ }^{61}$, der der Porträttypus einer strikt flächenbezogenen Profildarstellung mit nur geringer räumlicher Entfaltung entgegenkam. Unter diesen Voraussetzungen konnten sich die von Pisanello am Vorbild antiker Münzdarstellungen entwickelten Porträttypen in strikter Profildarstellung in der italienischen Malerei noch weit bis ins 15. Jahrhundert hinein als paradigmatische Porträtform halten.

Die nach 1441 entstandene »Medaille des Leonello d'Este" (Abb. 43) ${ }^{62}$ ist eine von fünf Medaillen, die das Profilbildnis des Markgrafen von Ferrara jeweils mit einer anderen humanistischen Botschaft auf der Rückseite der Münze verbindet. Auch wenn die markanten physiognomischen Züge hier mit neuer Beobachtung individueller Charakteristika plastisch durchdrungen sind, so ist das hohe Maß an darstellerischer Stilisierung in Verbindung mit der Isolation des Dargestellten sowohl zum Grund, wie zum Betrachter hin nicht zu übersehen. Der Dargestellte erscheint als Büste entrückt vor einem abstrakten, ortlosen Grund, den Blick unzugänglich nach links hin abgewendet, herausgenommen aus allen zeitlichen Bezügen eines handlungsbezogenen oder seelisch-regungshaften Dialogs mit dem Betrachter. Pisanello präsentiert das Individuum im repräsentativen Modus überzeitlicher Dauer. Diesen Porträtmodus hat Pisanello auch in seinen gemalten Bildnissen, etwa in dem »Bildnis des Leonello d'Este « 63 beibehalten. Zahlreiche italienische Künstler von Domenico Veneziano über Piero della Francesca, Botticelli bis zu den Pollaiuolos und Mantegna sind in ihren bedeutenden Porträtdarstellungen dieser Porträtform Pisanellos gefolgt ${ }^{64}$, auch wenn der Grad der Stilisierung dabei mit der Zeit abnimmt und die Darstellung zunehmend mit Elementen einer gesteigerten Wirklichkeitsbeobachtung angereichert wird. Freilich bleibt dieser Modus des Porträts in der italienischen Kunst ohne weiterführendes Entwicklungspotential auf dem Weg zu einer neuen Form des Individualporträts. Zu sehr waren die Ausdrucksmöglichkeiten durch die grundsätzlichen Festlegungen dieser Porträtform beschränkt ${ }^{65}$.

Das erste überlieferte autonome Bildnis in Italien, das den Menschen nicht im Profil, sondern mit erweitertem Körperausschnitt von vorne und mit dem Motiv eines potentiell agierenden Armes zeigt, ist Castagnos 


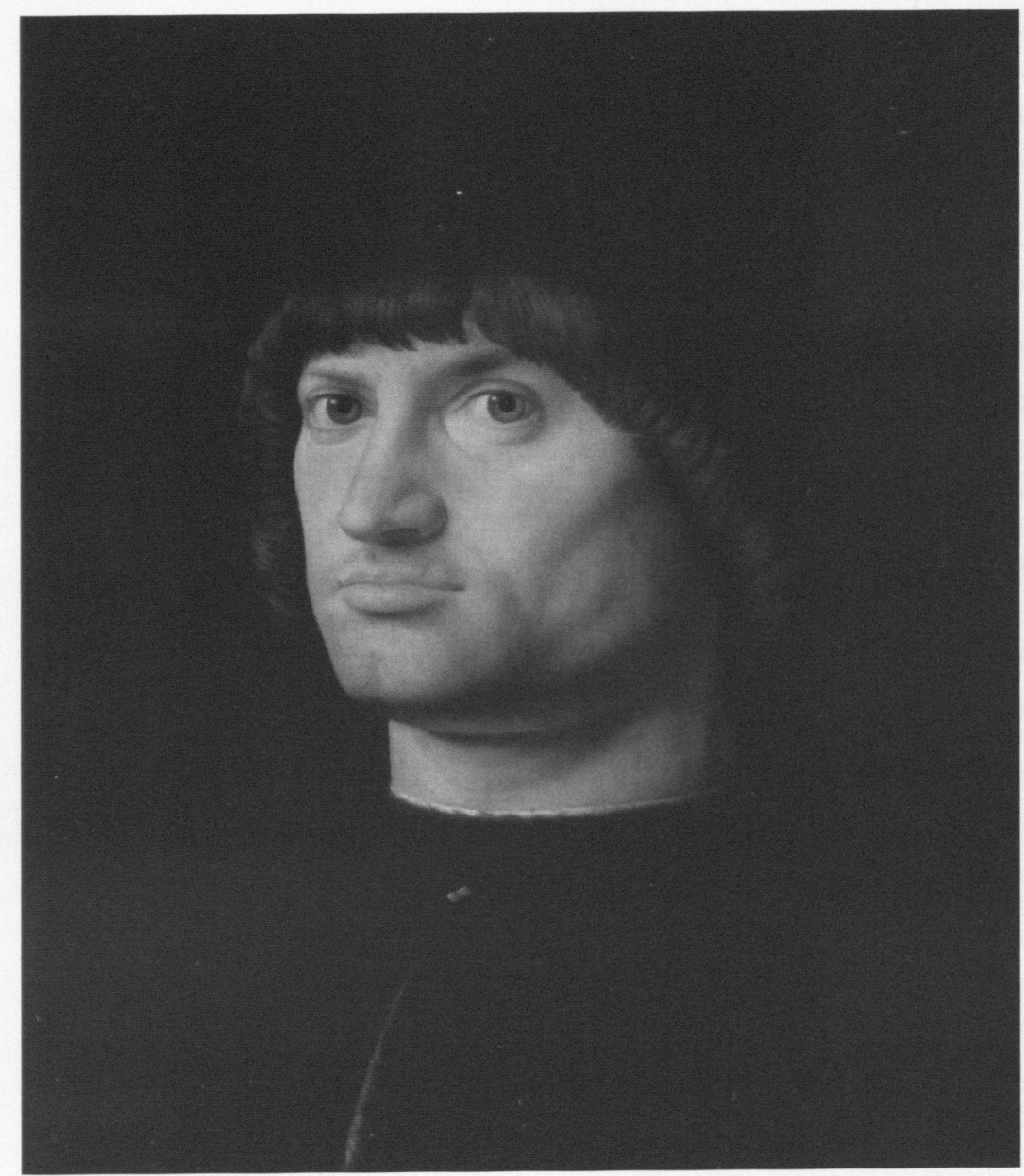

Abb. 45: Antonello da Messina, Bildnis eines Mannes ('Condottieres) (1475)

"Porträt eines Mannes « (Abb. 44) ${ }^{66}$, das in Castagnos letzten Schaffensjahren um 1450 entstand. Der Blick ist prüfend auf den Betrachter gerichtet, die markante Physiognomie augenscheinlich von einem individuellen Charakter getragen. Die Schilderung des Sichtbaren fällt viel weniger detailfreudig als in der altniederländischen Porträtmalerei aus, bleibt auf die Klärung und Durchbildung plastischer Einheiten und Zusammenhänge des Körperlichen konzentriert, ebenso öffnet sich der Körper nur wenig zum Raum als Entfaltungsort. Die Verwandtschaft einer solchen Darstellung mit den Assistenzfiguren in den zeitgenössischen Freskenzyklen mit Historiendarstellungen liegt auf der Hand. Und dennoch ist das potentiell handlungsbezogene Auftreten des Dargestellten in dieser Hinsicht nicht zu verorten, es ist nicht fremdbestimmt, sondern auf ein individuelles, ihm eigenes Vermögen bezogen, in dem sich eine neue Bestimmtheit des Individuellen konkretisiert: Die Bildregie dieses Porträts ist nicht nur von einer intensivierten Interaktion zwischen Dargestelltem und Betrachter getragen, sondern auch von einem komplexen anschaulichen Wechselverhältnis einzelner regungshafter Aspekte an Körper, Hand und Gesicht, die in ihrem visuellen Zusammenspiel die Suggestion eines National Gallery of Art (Mellon Collection), Inv. Nr. 1937.I.17. Vgl. Marita Horster: Andrea del Castagno. Complete edition with a critical catalogue, Oxford 1980, S. 181. 


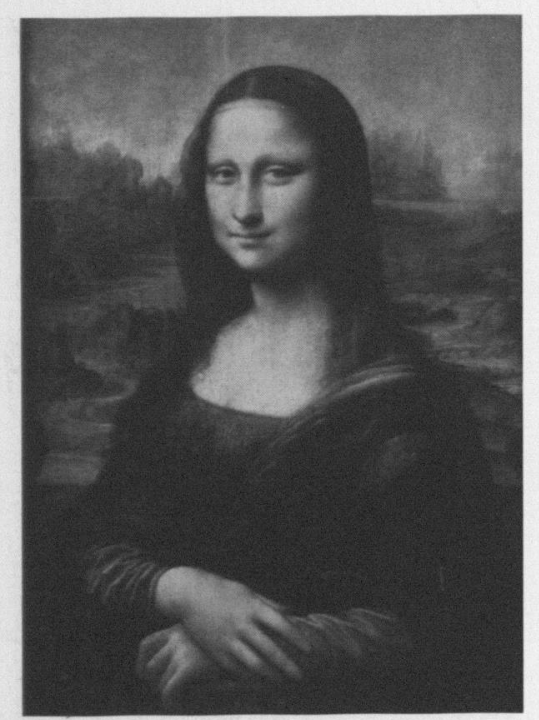

Abb. 46: Leonardo da Vinci, Mona Lisa (1503-05)

67 Ebd., S. $143 \mathrm{ff}$.

$68 \mathrm{Holz}, 36,2 \times 30 \mathrm{~cm}$, Paris, Louvre, Inv. Nr. 693. individuellen Vermögens entstehen lassen. Interessanterweise ist es gerade der im Vergleich zur altniederländischen Malerei reduzierte Grad an motivischer Detaillierung und analytischer Besonderung in der Deutung des Sichtbaren, der diese Interaktion für den Betrachter lebendig werden läßt, indem seine Anschauung die über Formentsprechungen aufeinander bezogenen physiognomischen Partien in einem lebendigen anschaulichen Prozeß aktiviert: Das Bildnis wandelte sich so von einer Bestandsaufnahme des Sichtbaren zu einem anschaulich erlebbaren Gleichnis des Lebendigen, das sich im Prozeß der Wahrnehmung in neuer Form für den Betrachter vergegenwärtigt und in seinen virtuellen Verknüpfungen diesem auch Dimensionen des Unsichtbaren in der Deutung eines Individuums vemittelt. Gerade dadurch, daß die Sichtbarkeit nicht vollständig, sondern nur in einem reduzierten Maße in das Medium der Malerei übersetzt wird, entstehen Spielräume für diese anschauliche Interaktion, in denen auf indirektem Wege etwas am Menschen sichtbar wird, was auf direktem Wege nicht darzustellen ist. Über diesen künstlerischen Ansatzpunkt, der von dem Darstellungsmodus der akribischen Komplettierung des Sichtbaren in der altniederländischen Malerei prinzipiell verschieden ist, haben die italienischen Maler zu einer abweichenden Deutung des Individuums in der Malerei gefunden, und in dieser Entdeckung liegt zugleich der wichtigste Ausgangspunkt für die weitere Gattungsentwicklung im 16. Jahrhundert.

Zwei Schlüsselfiguren dieser neuen Porträtauffassung sind Antonello da Messina und Leonardo da Vinci. Ausführlich hat in der jüngeren Forschung vor allem Gottfried Boehm Antonello da Messina (vgl. Abb. 45) noch einmal als Protagonisten der Genese einer neuen Porträtmalerei profiliert, ja an den »Ursprung der Gattung « und an den Anfang der "Herausbildung der modernen Idee des Porträts " gestellt ${ }^{67}$. Noch kompromißloser als seine Vorgänger in der altniederländischen und der italienischen Porträtmalerei hat Antonello da Messina den individuellen Menschen in seiner seelisch-körperlichen Einmaligkeit unter Absehung von äußeren Normierungen und lediglich akzessorischen Verortungen ins Zentrum seiner visuellen Recherche im Porträt gerückt, und den Dargestellten im Modus einer - auch durch die mimische Potentialität des Gesichtsausdrucks - lebendigen Präsenz gezeigt: Im »Bildnis eines Mannes « von 1475 (Abb. 45) ${ }^{68}$ sind äußere Hinweise auf die gesellschaftliche Stellung und berufliche Tätigkeit soweit reduziert, daß die volkstümliche Charakterisierung als »Condottiere « sich - ohne gesicherte Identifizierung - nur vermutungsweise auf die Narbe an der Oberlippe beziehen konnte. Wie schon Castagno vor ihm (vgl. Abb. 44) hat Antonello die Figur in der für die italienische Porträtmalerei neuen Dreiviertelansicht gezeigt, darüber hinaus ist die Figur - wie in allen Bildnissen Antonellos als Brustbild im kleinen Format nach links gewandt und ohne Hände hinter einer Brüstung dargestellt. Unverkennbar sind Impulse aus der altniederländischen Porträtmalerei Jan van Eycks, die Antonello während seiner Jahre am Hof des Königs von Neapel studieren konnte, zu entdecken, so das suggestive Helldunkel, das die Figur erscheinungshaft mit der Aura des Räumlichen und Zeitlichen umfängt, die Fokussierung des Verosimile in den Augen und das illusionistische Spiel mit der Brüstung als Realitätsgrenze des Bildes, die hier versehen mit dem >Leitfossik der venezia- 
nischen Kunst, einem Cardellino mit der Signatur »1475 ANTONELLUS MESSANEUS ME PINXIT «, erscheint. Ein Vergleich mit den Bildnissen Jan van Eycks (Abb. 41, 42) zeigt aber auch, daß die Bildnisse Antonellos mit einer neuen Entschiedenheit und Konzentration psychologische Aspekte in der seelischen Regungsfähigkeit des Dargestellten thematisieren und diese über eine qualitativ neue Interaktion des Sichtbaren entfalten. Diese grundsätzliche Errungenschaft in Antonellos Porträtmalerei liegt - mit Boehms treffenden Worten - darin, »mit der detaillierten Darlegung von anschaulichen Merkmalen (in Physiognomie und Körperhaltung) eine virtuelle Perspektive auf die - sonst völlig unsichtbare >Person< zu entwickeln. Die Malerei macht im Bildnis mittelbar sichtbar, was unmittelbar deswegen nie zu sehen ist, weil es mit keinem angebbaren >Punkt< des Menschen identisch sein kann. >Person< baut sich als Bedeutungskategorie in der dargestellten Figur auf, so wie wir sie realiter auch nur dann erfassen, wenn wir dem Menschen `begegnen`, mit ihm `kommunizieren< oder ihn >verstehen<, ihn als ihn selbst erfassen. Dieses >als< haben die Maler der Renaissance in die Form einer künstlerischen Bedeutungssprache übersetzt, Individualität damit in den Bereich der Erkenntnisleistung der Kunst gebracht. $\ll^{69}$

\section{Der Mensch als "schöpferischer Bildhauer" seiner selbst}

Der Künstler, der diesen neuen geistigen Anspruch an die malerische Darstellung des Menschen als erster auch umfassend theoretisch reflektiert hat, war Leonardo da Vinci: Mit Hilfe der äußeren Bewegungen müsse die Malerei die inneren Gemütsbewegungen eines Menschen versinnlichen und, mit einer Akribie, die ihresgleichen sucht, hat Leonardo an einer Phänomenologie der menschlichen Bewegungen und Regungen gearbeitet $^{70}$. Für Porträtmaler, die nur nach einer äußerlichen >Ähnlichkeit< strebten, hatte Leonardo nicht vielmehr als Verachtung übrig, da »ihre Sachen ohne Bewegung ("senza movimento «) seien ${ }^{71}$. Wirkungsvoll hat auch Leonardo seine Porträtfiguren mit Hilfe eines Helldunkels mit der Aura einer zeitlichen Erscheinung umgeben, in der sich, wie z. B. im Porträt der Mona Lisa ${ }^{72}$ (Abb. 46), die anschaulich fein ausbalancierten Potentialitäten des Mimischen stets von Neuem aktivieren. Dabei wird der Betrachter in einen anschaulichen Diskurs über die Persönlichkeit verstrickt, der - wie die ausgedehnte Rezeptionsgeschichte zeigt nicht in begrifflichen Bestimmungen stillzulegen ist, sondern den individuellen Menschen für jede Betrachtung aufs Neue in seiner Rätselhaftigkeit inszeniert. Auch wenn die dargestellte Persönlichkeit und der historische Hintergrund der Entstehung dieses Bildnisses ausführlich in den Quellen dokumentiert sind ${ }^{73}$, greift es zu kurz, das Porträt der Mona Lisa lediglich auf der Ebene der Darstellung einer historischen Persönlichkeit einer Florentiner Kaufmannsfrau zu betrachten. Vielmehr experimentiert Leonardo hier auf der Ebene einer übergeordneten anthropologischen Reflexion exemplarisch mit den komplizierten Verschränkungen von Abbild und Idealbild, von Menschlichem und Göttlichem: Die enigmatische Unzugänglichkeit dieses Bildnisses ist nicht angemessen zu verstehen,

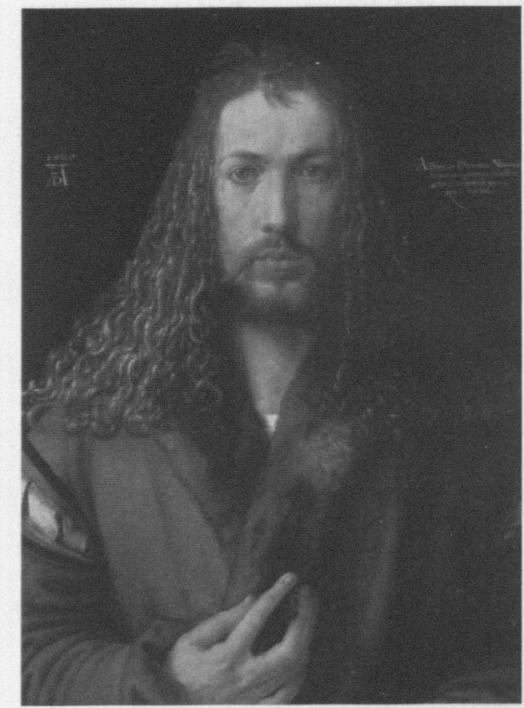

Abb. 47: Albrecht Dürer, Selbstbildnis im Pelzrock (1500)

69 G. Boehm: Bildnis und Individuum, S. $67 \mathrm{f}$.

70 Leonardo da Vinci: Trattato della pittura, hg. von G. Milanesi, Nachdruck der Ausgabe Rom 1890, o. O. 1989 , S. 58 f.

71 Leonardo: Trattato della pittura, S. 37, \$ 55.

72 1505- 1514, Holz, 77 x $53 \mathrm{~cm}$, Paris, Louvre. Vgl. G. Boehm: Bildnis und Individuum, S. 220 .

73 Siehe zu den historischen Hintergründen G. Vasari: Vite, Bd. IV, S. 39f. und resümierend Frank Zöllner: Leonardo da Vinci. Mona Lisa. Das Porträt der Lisa del Giocondo. Legende und Geschichte, 1994. 
74 Leonardo, Trattato della pittura, S. 16, S 21: -E tarto più supera gl'ingegni degli uomini ad amare ed innamorarsi di pittura che non rappresenta alcuna donna viva. E già intervenne a me fare una pittura che rappresentava un cosa divina, la quale comperata dal l'amante di quella volle levarne la rappresentazione di tal deità per poterla baciare senza sospetto*.

75 Selbstbildnis in Pelzrock, Lindenholz, $67 \times$ $49 \mathrm{~cm}$, signiert und datiert 1500, München, Alte Pinakothek, Inv. Nr. 537; Inschrift: $\gg$ Albertus Durerus Noricus / ipsum tme propriis sic effin/gebam coloribus aetaris/anno XXVIII (5o malte ich, Albrecht Dürer aus Nürmberg, mich selbst mit unvergänglichen Farben im Alter von 28 Jahren)*. Ausführliches Forschungsreferat in: G. Goldberg; B. Heimberg; M. Schawe, Albrecht Dürer. Die Gemälde in der Alten Pinakothek, München 1998, S. 315-353. Vgl. zur kulturgeschichtlichen Einordnung Richard van Dülmen: Die Entdeckung des Individuums. 1500-1800, Frankfurt 1997.

76 So die u. a. von Donat de Chapeaurouge (Der Christ als Christus. Darstellungen der Angleichung an Gott in der Kunst des Mittelalters, in: Wallraf-Richartz-Jahrbuch. Westdeutsches Jahrbuch für Kunstgeschichte, Bd.48/49 (1987/88), S. 77-96) vertretene These. Dieser Sichtweise haben schon Erwin Panofsky (Albrecht Dürer, Bd. 1, Princeton, New Jersey 1948, S.43) oder Fedja Anzelewsky (Düret-Studien. Untersuchungen zu den ikonographischen und geistesgeschichtlichen Grundlagen seiner Werke zwischen den beiden Italienreisen, Berlin 1983, S. 90) widersprochen

77 Giovanni Pico della Mirandola: De hominis dignitate. Öber die Würde des Menschen, übers. von N. Baumgarten, hg. von A. Buck, Hamburg 1990, S. 6f.: »Poteris in inferiora quae sunt bruta degenerare; poteris in superiora quae sunt divina ex tui animi sententia regenerari.* Auf diesen Hintergrund hat auch schon Klaus-Peter Schuster (Der Mensch als sein eigener Schöpfer. Dürer und Beuys oder: das Bekenntnis zur Kreativität, in: Süddeutsche Zeitung, 22./23. Juni 1985, S. 133) hingewiesen.

78 So nennt schon Leon Battista Alberti in seinem Traktat Della Pittura den Künstler *un altro iddio* (in: Ders.: Leone Battista Alberti's kleinere kunsttheoretische Schriften, Nachdruck der Ausgabe Wien 1877, hg. von H. Janitschek, Osnabrück 1970 (Quellenschriften für Kunstgeschichte und Kunsttechnik des Mittelalters und der Renaissance; 11) S. 91.

79 Vgl. E. Panofsky: Albrecht Dürer, S.43, F. Anzelewsky: Dürer-Studien, S. 92.

80 Bernardino Pinturicchio, Selbstbildnis, 1501, Fresko, Spello, Sa. Maria Maggiore. wenn man nicht berücksichtigt, daß das Helldunkel der Figur und der als irreale Landschaft dargestellte Weltgrund den Gattungshorizont des Porträts mit den Mitteln einer Bildmetaphorik des Göttlichen grundsätzlich übersteigen. Die geistesgeschichtliche Aktualität dieser Grenzverläufe in der anthropologischen Selbstbestimmung hat Leonardo selbst in einer ebenso anschaulichen wie skurrilen, vielleicht nur gut erfundenen Anekdote thematisiert: Auf Wunsch eines Auftraggebers habe er einmal ein Heiligen- oder Madonnenbild übermalen müssen, um ein Porträt daraus zu machen, damit dieser es ohne Scham küssen konnte ${ }^{74}$. Pointiert tritt hier die mögliche Labilität im Verhältnis der Darstellung des Göttlichen und Menschlichen zu Tage, eine Labilität, die - auch das wird bei Leonardo deutlich - letztlich durch den Maler und seine Kunst entschieden wird.

Vor diesem problemgeschichtlichen Hintergrund ist auch das Selbstbildnis von Albrecht Dürer aus dem Jahre 1500 (Abb. 47) ${ }^{75}$ zu verstehen, das in seiner christusbildähnlichen Stilisierung eines Frontalbildnisses nicht als blasphemisches Dokument einer hybriden Anmaßung eines Künstlers ${ }^{76}$, sondern als Schlüsselwerk eines anthropologischen Selbstverständnisses zu deuten ist, das in neuer Form von der utopischen Idee der selbstverantwortlichen Freiheit und Selbstbestimmtheit des Menschen getragen ist. Pico della Mirandola hat diese Vorstellung in prominente Worte gefaßt, wenn er in seiner 1486 verfaßten Rede Über die »Würde des Menschen « den Menschen als »plastes et fictor ", als »schöpferischen Bildhauer seiner selbst « beschreibt und dieser humanistischen Selbstbestimmung des Menschen die Mahnung mit auf den Weg gibt: »Du kannst zum Niedrigeren, zum Tierischen entarten; du kannst aber auch zum Höheren, zum Göttlichen wiedergeboren werden, wenn deine Seele es beschließt. « ${ }^{77}$ Beflügelt von der schon seit dem 15. Jahrhundert als Topos verbreiteten Analogie zwischen Gott und dem Künstler als zwei miteinander verwandten Schöpfern ${ }^{78}$, hat Dürer hier die anschauliche Angleichung seiner Gestalt an das Christusbild und die idealisierende Stilisierung seiner Körperformen in klaren Symmetriebildungen und Proportionen im Zuge einer aktualisierten Imitatio Christi ${ }^{79}$ gestaltet: Die künstlerische Form dieses Bildnisses ist als ethischer Imperativ zu lesen! Darüber hinaus hat sich Dürer in der fast sensualistischen Bestandsaufnahme des Sichtbaren, in der reduzierten Farbigkeit vor dunklem Grund und in der Fokussierung des Gesichtes, die in der Metaphorik des Auges als >Fenster der Seele< kulminiert, bewußt an Darstellungsmodi des altniederländischen Porträts orientiert. Auch dies sind Bestandteile einer in der künstlerischen Sprache selbst angelegten Selbststilisierung. Es zeugt - so paradox es scheinen mag - von der neugewonnenen Konsolidierung des Gattungsstatus und der künstlerischen Form des Porträts, daß die Künstler auf dem Boden der Porträtmalerei auf jeweils unterschiedliche Weise mit den Gattungsgrenzen des Porträts zu experimentieren begannen und dabei malend neue anthropologische Verortungen des Menschen erkundeten.

Nur ein Jahr nach Dürers Selbstbildnis ist Pinturicchios Selbstbildnis in Spello ${ }^{80}$ entstanden (Abb. 48), das auf andere Weise, mit einer noch stärker in den Traditionen einer mit symbolisch-attributiven Verweisen arbeitenden Bildsprache das Thema der ethischen Selbststilisierung des Ma- 
lers aufgreift. Als Signatur-Selbstbildnis in den Kontext einer freskierten Kapelle eingefügt ist es von Elementen eines Trompe-l'œil-Stillebens umgeben, die das Porträt indirekt mit ethischen Implikationen aufladen: Während sich Pinturicchio in seinem Selbstbildnis im nüchtern-asketischen Modus eines schwarzen Malergewandes mit schwarzer Mütze und ohne jegliches Dekorum darstellt, ist sein Name hoheitsvoll latinisiert auf einer goldgerahmten tabula ansata gleichsam all'antica präsentiert: Es ist die Kunst, die diesem Menschen seinen Adel verleiht. Wie kostbare Präziosen sind die Pinsel an Korallenketten hängend unter dem Bild dekoriert. Die über dem Bildnis auf einem mit illusionistisch drapierten Tüchern geschmückten Bord dargestellten Bücher weisen Pinturicchio als ebenso gebildeten wie gottesfürchtigen - seiner eigenen Vergänglichkeit als Mensch mit Blick auf die erloschene Kerze bewußten - Maler aus, der im Text des aufgeschlagenen Buches den Schutz Gottes für sich und seine künstlerische Hand erbittet.

\section{Ethos und Ästhetik: Die Metaphorisierung der malerischen Mittel in der Hochrenaissance}

In der Porträtmalerei der Hochrenaissance erreicht die Verschmelzung der ethischen Deutung mit der ästhetischen Darstellung des Menschen eine neue Qualität, indem sie auf dem Wege einer umfassenden Metaphorisierung aller Darstellungsaspekte das Bildganze solchermaßen durchdringt, daß vor dem Hintergrund einer reich entwickelten Sichtbarkeitsmetaphorik, die sich in neuer Form auch aus antiken Quellen speist, die Maler auf attributive Erläuterungen auf der Ebene eines äußerlich-akzessorischen symbolischen Inventars weitgehend verzichten konnten ${ }^{81}$ (vgl. Abb. 49, 50): Die dargestellten Individuen beginnen scheinbar aus sich selbst heraus zu sprechen, selbst wenn sie als historische Persönlichkeit nicht mehr identifizierbar sind. Während die Porträtmalerei im Quattrocento ihre größten Erfolge in der Darstellung und geometrischen Stilisierung des Äußeren, in der etappenweise Erschließung des menschlichen Körpers für das Bildnis und in der mehr oder weniger minutiösen Erkundung des Volumens und der Oberfläche, des relievo des menschlichen Gesichts mit seiner mimischen Charakterisierung und der künstlerischen Integration dieser optischen Wirklichkeitsnotizen erreichte, wendeten sich die Künstler in den Darstellungen des Menschen seit dem frühen 16. Jahrhundert verstärkt der Vergegenwärtigung und Erkundung des Inneren als neuem Hauptproblem der Darstellung zu. Visuelle Metaphern für das Lebendige, das Seelische, das Spirituelle, das Hintergründige und Verborgene im Menschen, seine "segreti interni«(Dolce), wurden gesucht.

An die Stelle des analytischen Blicks auf das Sichtbare im 15. Jahrhundert tritt im 16. Jahrhundert ein neues Synthesebedürfnis in der Deutung des Menschen mit anschaulichen Mitteln: Alle malerischen Mittel bis hin zur Farbigkeit sind an dieser metaphorischen Deutung des Individuums beteiligt. Und die umfangreichen Systematisierungen zu den Formen und Farben von Augen, Ohren, Nasen, Kinnpartien, Augenbrauen in dem 1504 publizierten Traktat »De Sculptura« von Pomponius Gauricus

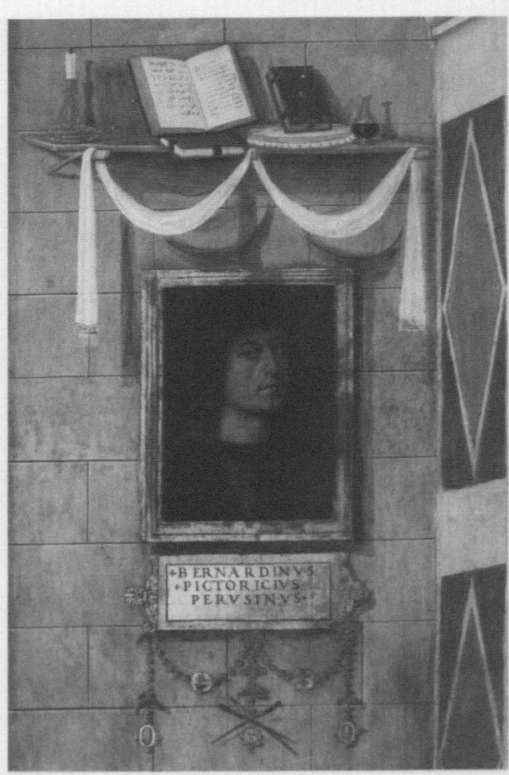

Abb. 48: Bernardino Pinturicchio, Selbsbildnis (1501)

81 Hierzu weiterführend Ch. Wagner: Farbe und Metapher, S.13-56, 237-306 und Ch. Wagner: Homo absconditus, S. $50 \mathrm{ff}$. 


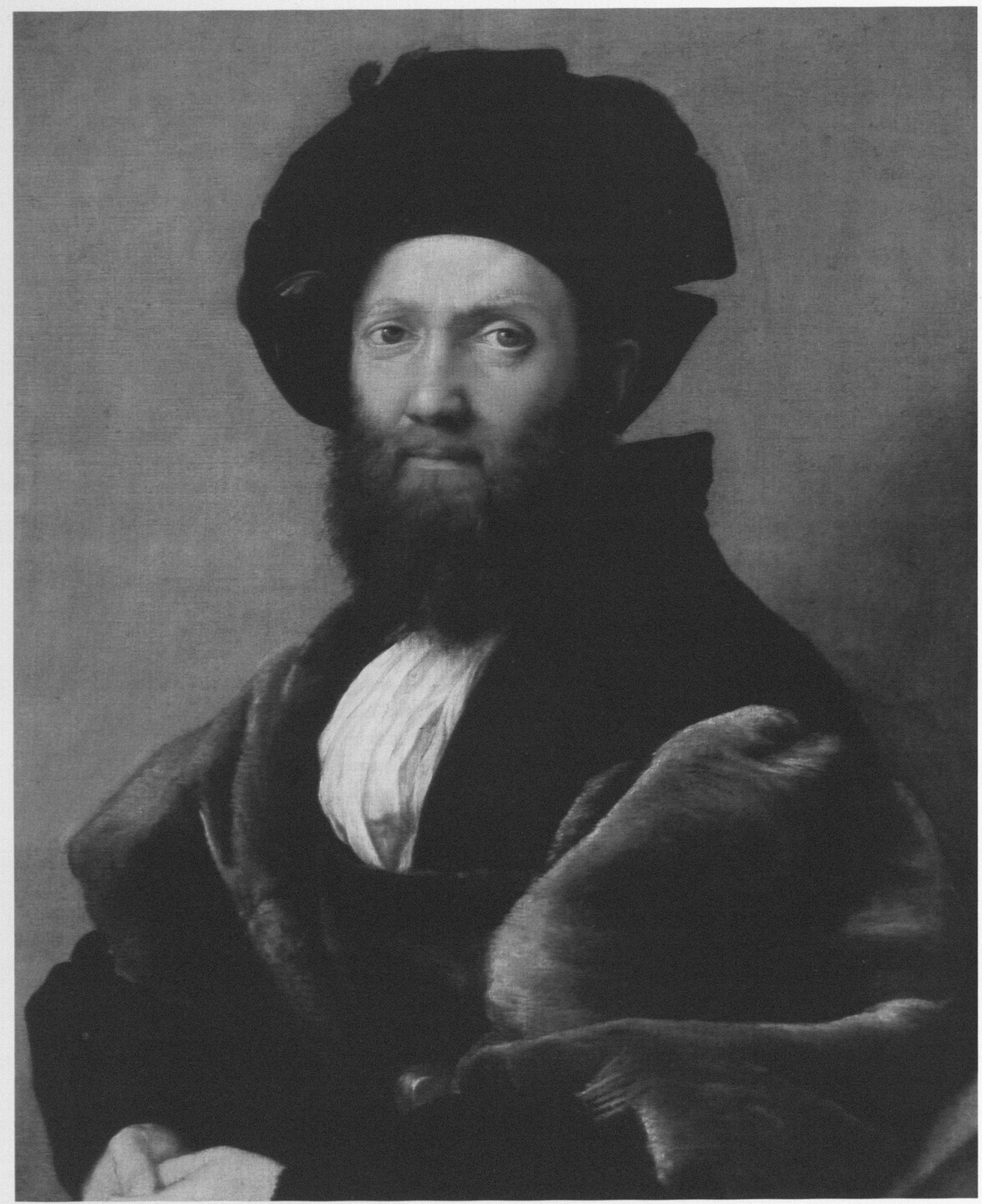

Abb. 49: Raphael, Baldassare

Castiglione (1514/15) 
dokumentieren eindrucksvoll, wie sehr man glaubte, auf diesem Wege die Qualitäten der Seele aus den Zügen des Körpers ablesen zu können ${ }^{82}$. Im Bildnis Baldassare Castigliones (Abb. 49), das vermutlich im Winter 1514/15 entstand, als sich Castiglione als Gesandter von Urbino am päpstlichen Hof in Rom aufhielt ${ }^{83}$, hat Raphael die Inkarnatfarbigkeit so kunstvoll in eine nuancierte Neutral- und Halbneutralfarbigkeit eingebettet, daß die Koloristik des gesamten Bildes in den Farben des Gesichtes und der Augen zu kulminieren scheint: Programmatisch steht die Farbe des menschlichen Leibes, das Inkarnat, im Zentrum einer humanistischen Deutung des Menschen. In anderen Porträts sind die Dargestellten über die Inkarnatfarbigkeit in ihrem Temperament charakterisiert $^{84}$. Darüber hinaus hat Raphael Baldassare Castiglione unterschwellig in Übereinstimmung mit den idealen Geometrien des Bildgefüges dargestellt. Es scheint, daß Castiglione in dieser idealen Geometrie die ethischen Normen, die er in seinem »Libro del Cortegiano" am Beispiel eines idealen Hofmanns beschreibt, anschaulich verkörpert. Anders als z. B. in Dürers Selbstbildnis (Abb. 47) und in früheren Bildnissen tritt diese Stilisierung aber nicht mehr als Kunstgriff der malerischen Darstellung, als personal- bzw. zeitstilistische Typisierung hervor, sondern wird in neuer Form Bestandteil der Erscheinung des Individuellen: Im Schein der >bloßen Erscheinung der Dargestellten hat Raphael seine metaphorische Deutung der Porträtierten in die Darstellung des Sichtbaren eingeführt, ohne selbst vordergründig als Deutender in Erscheinung zu treten. Bis in die dynamische Struktur der malerischen Ausführung der einzelnen Pinselzüge hat Raphael dabei die Figur Castigliones auch mit der Suggestion einer sich anschaulich verlebendigenden Regungsfähigkeit versehen, für die er an vielen Stellen - wie z. B. an der Hand und im Gewand - die Schilderung des motivischen Details bewußt reduzierte: Diese anschauliche Suggestion von Lebendigkeit haben schon die Zeitgenossen als ästhetisches Schlüsselphänomen des Porträts beobachtet und im Topos des »non so che beschrieben $^{85}$, etwa wenn Castiglione in einem Gedicht für seine Ehefrau Ippolita Torella umschreibt, daß sein Bildnis mit ihr während seiner leiblichen Abwesenheit zu lächeln, ja zu sprechen scheine ${ }^{86}$.

Wie sehr sich Castiglione selbst der intellektuellen Leistung der Deutung des Menschen in seiner visuellen Darstellung durch die Künstler und der anspruchsvollen Auffassung des Porträts als Spiegel des Lebendigen bewußt war, belegen die einleitenden Sätze aus seinem »Libro del Cortegiano«: Während Castiglione seine literarische Schilderung des Hofes von Urbino bescheiden "ein gemaltes Porträt, von der Hand eines unwürdigen Malers, der im Gegensatz zu Raphael und Michelangelo nur die Hauptlinien zu ziehen vermöge «nennt, seien diese Maler im stande, die Wahrheit »mit anmutigen und übergänglichen Farben zu schmücken, und [...] durch die Kunst der Perspektive das erscheinen zu lassen, was nicht ist ${ }^{87}$. Dabei hebt Castiglione - ebenso wie später Dolce - hervor, daß die Porträtdarstellung den Schein des Lebendigen nicht zuvörderst auf dem Wege einer übermäßigen motivischen Detaillierung - wie noch in der Porträtmalerei des 15. Jahrhunderts -, sondern gerade durch eine gewisse malerische Freiheit, die er »vaghezza« nennt, zu vermitteln vermöge. Daß Castiglione dabei auch die umfassende Metaphorisierung der malerischen

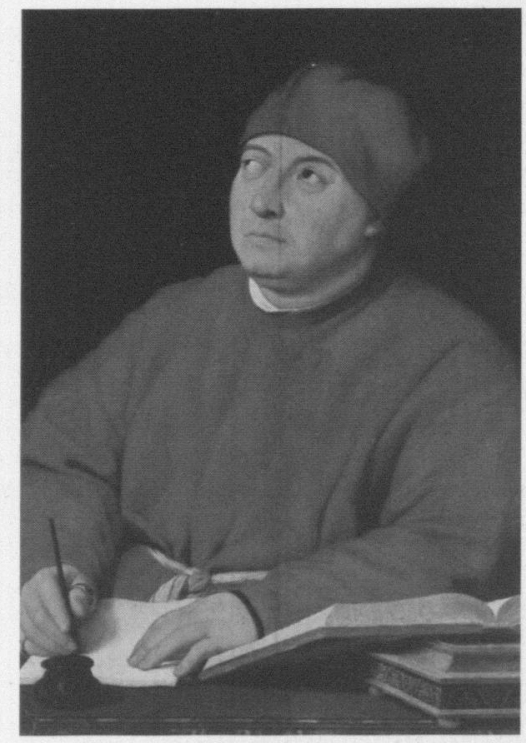

Abb. 50: Raphael, Tommaso

Inghirami (1511/12)

82 Pomponius Gauricus: De sculptura, hg. von A. Chastel und R. Klein, Genf 1969 (Hautes études médiévales et modernes; 5), S. 129, 147, 161. Vgl. L. Dolce: Dialogo della pittura, S. 153.

83 Leinwand, $82 \times 67 \mathrm{~cm}$, Paris, Louvre, Inv. Nr. 611. Vgl. John Shearman: Castiglione's portrait of Raphael, in: Mitteilungen des Kunsthistorischen Institutes in Florenz 38 (1994), S. 69-97.

84 Vgl. Ch. Wagner: Farbe und Metapher, S. 237306.

85 Raphael selbst hat sich hierzu 1516 in seinem berühmten Brief an Castiglione zur certa idea geäußert (Erwin Panofsky: Idea. Ein Beitrag zur Begriffsgeschichte der älteren Kunsttheorie, Berlin 1985, S. 31ff.).

86 Siehe die Quelle bei Vincenzo Golzio ( $\mathrm{Hg}$.): Raffaello nei documenti, nelle testimonianze dei contemporanei e nella letteratura del suo seculo, Città del Vaticano 1936, Nachdruck $1971, \mathrm{~S} 43$.

87 Baldassar Castiglione: Das Buch vom Hofmann, übers. von F. Baumgart, München 1986, S. 3. Ders.: Libro del Cortegiano, hg. von G. Carnazzi, Mailand 1987, S. 50: mandovi questo libro come un ritratto di pittura della corte d'Urbino, non di mano di Rafaello o Michel Angelo, ma di pittor ignobile e che solamente sappia tirare le linee principali, senza adornar la verità de vaghi colori o far parer per arte die prospettiva quello che non è«. 
88 B. Castiglione: Das Buch yom Hofmann, S. 113f. Ders.: Libro del Cortegiano, S. 122: -Però è necessario che'l nostro cortegiano [...] non solamente ponga cura d'aver in sé parti $e$ condizioni eccellenti, ma il tenor della vita sua ordini con tal disposizione, che'l tutto corrispondz a queste parti [...] di sorte che ogni suo atto risulti e sia composto di tutte le virtì [...]; Peró bisogna che sappia valersene, e per lo paragone e quasi contrarietà dell'una talor far che l'altra sia più chiaramente conosciuta, come i boni pittori, i quali con l'ombra fanno apparere e mostrano i lumi de' rilevi, e così col lume profundano l'ombre dei piani e compagnano i colori diversi insiem di modo, che per quella diversità l'uno e l'altro meglio si dimostra, e 'l posar delle figure contrario l'una all'altra le aiuta a far quell'officio che è intenzion del pittore.

89 B. Castiglione: Libro del Cortegiano, S. 84: * Spesso ancor nella pittura una linea sola non stentata, un sol colpo di penello tirato facilmente, di modo che paia che la mano, senza esser guidata da studio $o$ arte alcuna, vada per se stessa al suo termine secondo la intenzion del pittore, scopre chiaramente la eccellenzia dell'artifice*.

90 B. Castiglione: Libro del Cortegiano, S. 80f. Vgl. L. M. Louden: Sprezzatura in Raphael and Castiglione, in: Art journal 28 (1968), S. 43-49.

91 L. Dolce: Dialogo della pittura, in: P. Barocchi (Hg.), Trattati d'arte del Cinquecento, 1960, Bd. 1, S. 185.

92 So resümiert Giovanni de' Rinaldi am Jahrhundertende zum Porträt: *Si può far conoscere l'interno dell'animo con il colorato esterno* (Il mostruosissimo mostro, zitiert nach: $\mathrm{P}$. Barocchi (Hg.): Scritti d'arte del Cinquecento, Bd. 2, Mailand-Neapel 1973, S. 2314 (La letteratura italiana. Storia e testi; 32/2).

93 B. Castiglione: Libro del Cortegiano, S $140 f$., M. Equicola: Libro di natura d'amore, zitiert nach: P. Barocchi (Hg.): Scritti d'arte del Cinquecento, S. 2156. Coronato Occolti: Trattato de' colori, zitiert nach: $\mathrm{P}$. Barocchi (Hg.): Scritti d'arte del Cinquecento, S. 2156, 2198ff., 2204.

94 L. Dolce: Dialogo della pittura, S. 152: >Dipinge non di meno i pensieri e gli affetti dell'2nimo comprendono $[\ldots]$ o per altri segni appariscono $\mathrm{i}$ segreti internik.
Mittel und die Verbindung von ethischen und ästhetischen Kategorien reflektierte, ist interessanterweise an den anthropologischen Metaphern, die er in der Analyse des idealen Hofmanns im "Libro del Cortegiano" verwendete, abzulesen: Ein vorbildlicher Hofmann solle seine Tugenden so zeigen, wie gute Maler Licht und Schatten und die Farben verteilen, der Hofmann »trage nicht allein Sorge dafür, in sich ausgezeichnete Gaben und Eigenschaften zu haben, sondern ordne seine Lebenshaltung derart, daß [...wie bei den] guten Maler[n], die die Lichter der erhabenen Teile durch Schatten erscheinen lassen und [...] die verschiedenen Farben derart zusammen [ordnen], daß gerade durch die Verschiedenheit die einen wie die anderen besser in Erscheinung treten ${ }^{88}$. Die metaphorische Vorstellung von der gelungenen Farb- und Hell-Dunkel-Gestaltung der Malerei als paradigmatisches Bild des tugendhaften Menschen ist eine genuine anthropologische Denkfigur dieser Zeit, und sie dokumentiert die wechselseitige Übertragbarkeit der ethischen und ästhetischen Kategorien in der Hochrenaissance. Auch das für ihn zentrale ethische Ideal der »sprezzatura «, der ,Lässigkeit<, erläutert Castiglione in einem ebenso kühnen wie modernen metaphorischen Vergleich mit der Farbgestaltung in der Malerei, indem die von ihm gewünschte Lässigkeit im Auftreten der »Mühelosigkeit hingeworfener Pinselstriche« entsprechen solle ${ }^{89}$. Es gehört in diesem Zusammenhang zu den aufschlußreichen geistesgeschichtlichen Pointen, daß Lodovico Dolce schon wenig später Castigliones Begriff der »sprezzatura von einer ethischen in eine ästhetische Kategorie zurückverwandelte, um damit metaphorisch die vollendete Farbgestaltung zu beschreiben: Wie die sprezzatura im menschlichen Verhalten die Mitte zwischen den Extremen von Nachlässigkeit und zu großer Angestrengtheit sichern solle ${ }^{90}$, so empfiehlt Dolce dem Maler die sprezzatura mit Blick auf die Farbigkeit als Mittelweg zwischen einer zu forcierten Unbestimmtheit (vaghezza) und einer übertrieben glatt ausmodellierten Farbgestaltung, die er »politezza« nennt ${ }^{91}$.

In diesen - hier nur exemplarisch angedeuteten - vielfältigen wechselseitigen Verbindungen von sittlichen Aspekten und sinnlichen Kategorien der Kunst wurde in der Renaissance eine neue Basis für die anschauliche Deutung eines Individuums und seines >unsichtbaren Inneren hinzugewonnen. Die hierdurch im 16. Jahrhundert veränderte Gattungserwartung an das Porträt spiegelt sich auch in den diesbezüglichen kunsttheoretischen Äußerungen von Lodovico Dolce bis Giovanni de Rinaldi $^{92}$ : Wie viele andere forderten beide von den Porträtmalern, daß man die "segreti interni* bzw. das Innere des Geistes in der äußeren Erscheinung ablesen können müsse. Ja Baldassare Castiglione, Mario Equicola oder Coronato Occolti haben das Problem, auf welche Weisen man am besten sein Wesen im Äußeren zum Ausdruck bringen könne, sogar auf der Ebene von Empfehlungen für die Kleidung reflektiert ${ }^{93}$. Als »poeta mutolo« dürfe sich der Porträtmaler - so Dolce - nicht auf die Schilderung der Außenseiten des Körpers beschränken, sondern er habe auch die Gedanken und Regungen des Geistes zu malen ${ }^{94}$.

Auf welche Weisen die Maler diesen Anspruch in ihren Porträtdarstellungen umgesetzt haben, ist mit Bezug auf die ebenfalls in der visuellen Kultur der Renaissance bedeutende Lichtmetaphorik exemplarisch in Raphaels Bildnis des Schriftgelehrten Tommaso Inghirami 


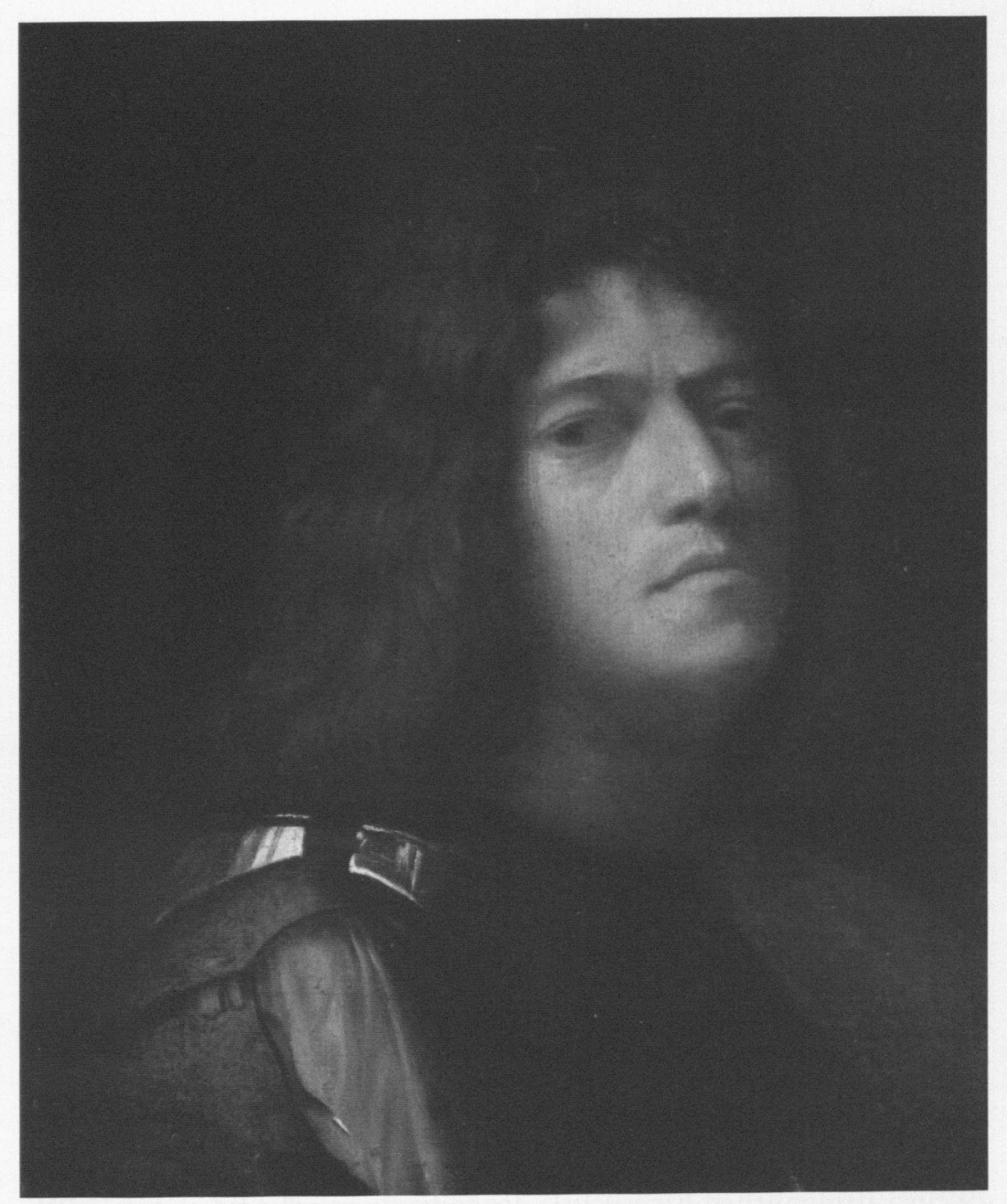

(Abb. 50 $)^{95}$ zu studieren: Das durch einen Augenfehler entstellte Gesicht des Humanisten hat Raphael so im Blick nach oben gewendet, daß das Schielen in der perspektivischen Fluchtung in die erzählerische Suggestion mündet, daß sich der Dargestellte einem irreal hellen Licht links oben außerhalb des Bildes zuwendet. Mit schreibbereiten Händen sitzt er, mit Tinte und Feder ausgestattet, an seinem Schreibpult vor einem unbeschriebenen Blatt Papier und einem aufgeschlagenen Buch, im kreativen Augenblick zwischen Lesen und Schreiben scheinbar innehaltend: In dieser erzählerischen Disposition und Lichtmetaphorik ist die Inspiration des Schriftgelehrten thematisiert. Raphael konnte bei dieser anschaulichen Deutung unmittelbar an eine im 16. Jahrhundert allgemein bekannte Lichtmetaphorik des »lumen naturale«, der >Verstandeshelle eines Menschen anknüpfen. Die Helle des Gesichts ist im Bildnis Tommaso Inghiramis nicht mehr ein überindividuelles Phänomen der Porträtgestaltung, wie in den idealisierten, oft nur reliefhaft modellierten italienischen Porträts des 15. Jahrhunderts, in denen die Helle eine theologisch begründete Teilhabe des Menschen am göttlichen, transzendenten Licht thematisierte, sondern sie wird in ihrer Ausprägung, Verteilung, aber auch Gefährdung
Abb. 51: Giorgione, Selbstbildnis als David (1510)
Holz, 62,3 x 89,5 cm, Florenz, Galleria Palatina, Nr. 171. 


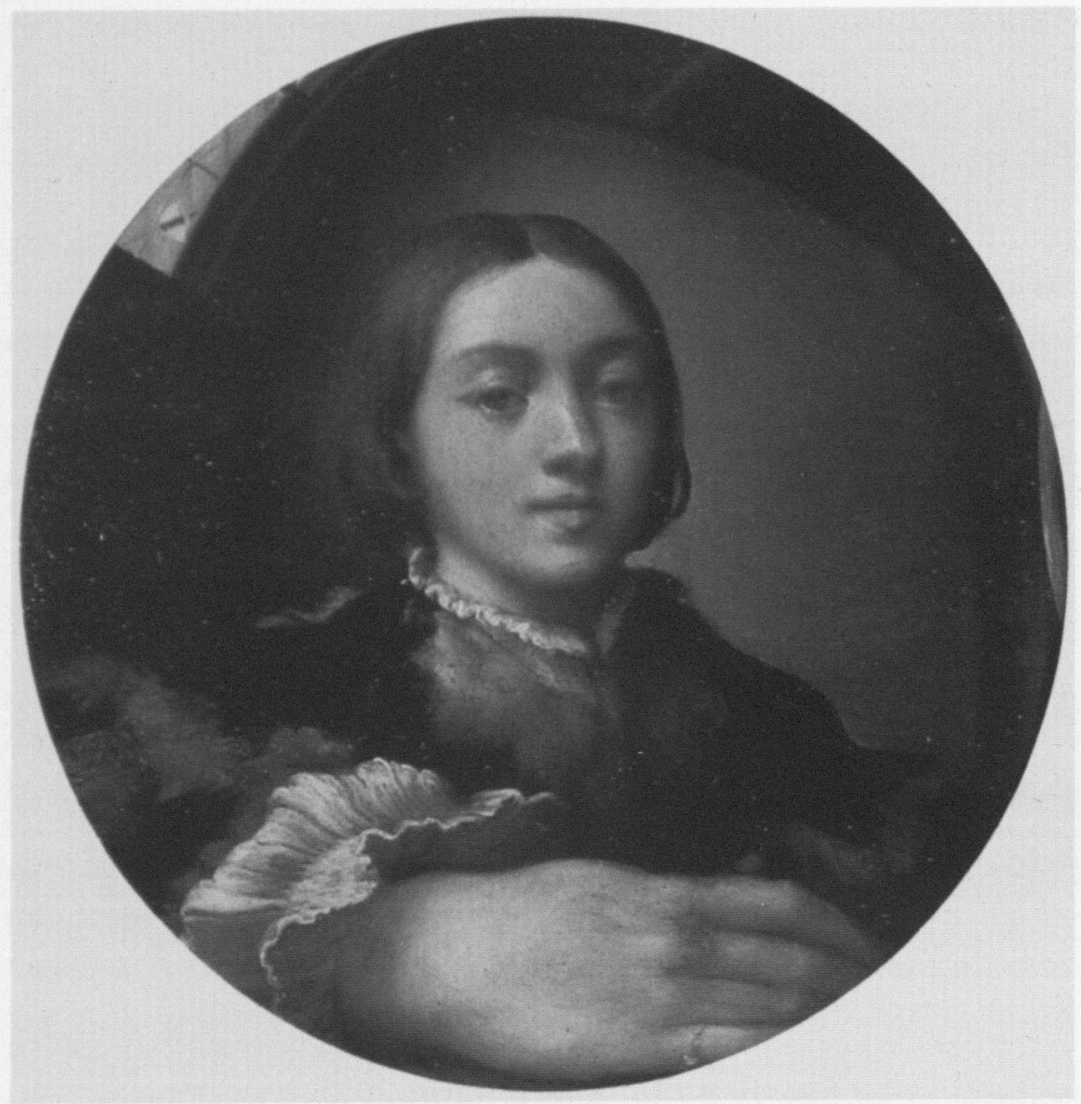
vid C. Lindberg: Auge und Licht im Mittelalter. Die Entwicklung der Optik von Alkindi bis Kepler, Frankfurt a. M. 1987; Werner Beierwaltes: Lumen naturale, in: Historisches Wörterbuch der Philosophie, hg. von J. Ritter und K. Gründer, Bd. 5, Darmstadt 1980, Sp. 547ff.; Hans Blumenberg: Licht als Metapher der Wahrheit. Im Vorfeld der philosophischen Begriffsbildung, in: Studium generale 10 (1957), S. 432-447. André Chastel: Marsile Ficine et l'art, Genf 1975, S. $81 \mathrm{ff}$.

97 Carolus Bovillus: Liber de sapiente, hg. von R. Klibansky, wiederabgedruckt in Ernst Cassirer: Individuum und Kosmos in der Philosophie der Renaissance (1927), Darmstadt 1987 , S. $299-412$, S. 354. zu einer persönlichen Eigenschaft des Individuums ${ }^{96}$. Das »lumen naturale« des Menschen wird bildmetaphorisch individualisiert, wird zur Verstandeshelle als persönlicher Eigenschaft.

\section{Die Entdeckung der Unergründlichkeit des Menschen}

Origineller noch als die anthropologische Metaphorisierung des Lichtes fällt in der Porträtmalerei der Renaissance die Deutung des Menschen mit Hilfe einer neuen Metaphorik der Dunkelheit und der Schatten aus: Dunkelheit und Schatten wurden im 16. Jahrhundert zu bedeutenden visuellen Metaphern der anthropologischen Selbstreflexion, indem sie sich bei Pico della Mirandola, Lorenzo Valla oder Carolus Bovillus mit der positiven Idee der für den Menschen prinzipiell kennzeichnenden Offenheit, Potentialität und Unergründlichkeit verbanden ("umbra et potentia «) 97 . Diese Sichtbarkeitsmetaphorik der anthropologischen Selbstreflexion ist unmittelbar auch in die Darstellung des Menschen in der Bildniskunst eingegangen. Gerade in der Dunkelheit entdeckten die Maler des frühen 16. Jahrhunderts eine für die neuzeitliche Selbstdeutung des Menschen eigentümliche, neue anthropologische Dialektik: In der Dunkelheit verschränkt sich die zeitlich bedingte Endlichkeit des Menschen mit der 
Unendlichkeit im Versuch seiner eigenen Selbsterkenntnis. Daß der Mensch sich selbst trotz seiner Begrenztheit unergründlich wird, dafür wird die Metapher der partiell undurchdringlichen Verschattung seines Bildnisses zur anschaulichen Chiffre ${ }^{98}$.

Radikaler als jeder andere seiner Malerkollegen hat Giorgione aus dieser Neubewertung der Dunkelheit Konsequenzen für seine anthropologische Deutung der Dargestellten im Porträt gezogen: Unter den Vorzeichen einer geistesgeschichtlichen Abkehr von einer einsinnig negativen symbolischen Bewertung der Dunkelheit, wie sie lange Zeit auch die Bildnisdarstellungen bestimmte ${ }^{99}$, hat Giorgione den Menschen in seinen Bildnissen in eine umfassende Dunkelheit eingebunden, die zugleich seine Unergründlichkeit und Vergänglichkeit in neuer Form anschaulich erfahrbar macht. Dies geschieht auch dadurch, daß Giorgione das interaktive Verhältnis zwischen dem Porträtierten und dem Betrachter neu definiert: Nicht selten ist es in seinen Bildnissen der Dargestellte, der sich in einer höchst transitorischen Wendung dem Betrachter zuwendet und nicht umgekehrt. Die Betrachtung des Dargestellten geschieht gleichsam unter seinen Bedingungen. Dies ist in dem zu. Unrecht angezweifelten, fragmentarischen Selbstporträt als David (Abb. 51) von $1510^{100} \mathrm{zu}$ sehen, in dem sich Giorgione erscheinungshaft eingebunden in eine alles umfassende Dunkelheit, die - anders als z. B. in Leonardos Helldunkel - auch partiell physiognomische Details des Gesichts erfaßt, ja partiell als formverzehrende Dunkelheit an die Stelle des Physiognomischen tritt, zeigt. Die extrem verzeitlichte Transitorik des Sichtbaren ist durch die scharf aufblitzenden Reflexlichter der Rüstung und die übermächtige Gegenwart der Dunkelheit akzentuiert. Die potentielle körperliche Drehung mit der sich der Dargestellte zum Betrachter zurïckwendet, hält die anschauliche Möglichkeit offen, sich jederzeit vom Betrachter abzukehren und in der Dunkelheit zu verschwinden. Das Helldunkel ist hier als zeitliches Erscheinungsmedium alles Sichtbaren gedeutet, dessen Fluchtpunkt die Dunkelheit ist. Die in der Renaissance selbstbewußt behauptete >Mündigkeit< des Menschen mündet hier in die Einsicht der Unergründlichkeit des Individuums, und in Giorgiones neuartiger Deutung der Dunkelheit als Erscheinungsgrund des Individuums ist der unauslotbare, >verschattete Grund des dargestellten Menschen, den schon Lorenzo Valla in der Metapher eines »aerario absconditam« als Voraussetzung des freien Willens des Menschen herausgearbeiter hatte, anschaulich mit gegenwärtig. ${ }^{101}$ Giorgione hat sich in seiner Vergänglichkeit und Unergründlichkeit gleichsam in die anschauliche Transitorik des Helldunkels eingeschrieben. Die existentielle Qualität dieser zeitbezogenen Selbstdeutung des Menschen ist auch z. B. an Giorgiones Darstellung einer alten Frau, "La vecchia ${ }^{102}$, abzulesen, die im Grenzbereich zwischen Allegorie und Porträt dem Betrachter mit ihrem Motto »Col tempo « und dem ergreifend scheinbar sprechend geöffneten und nahezu zahnlosen Mund nicht nur die Zeitbedingtheit ihrer eigenen, sondern der menschlichen Existenz schlechthin vor Augen stellt.

Die Eigentümlichkeit, daß sich Giorgione in seinem Selbstbildnis als David porträtierte, ist anders als in der langen Tradition der Selbstbildnisse in assistenza ${ }^{103}$ zu verstehen. Denn zum ersten Mal erscheint hier ein Mensch im Rahmen eines autonomen Selbstbildnisses in mythologischer
98 Hierzu weiterführend $\mathrm{Ch}$. Wagner: Homo absconditus, S. $39 \mathrm{ff}$.

99 Ebd., S. 52ff.

100 Leinwand, $52 \times 43 \mathrm{~cm}$, Braunschweig, Herzog Anton Utrich-Museum, Inv.-Nr. 454. Vgl. zur Diskussion um die Zuschreibung Terisio Pignatti: Giorgione. Werk und Wirkung, Stuttgart 1979, S. 155 f.

101 Lorenzo Valla: Über den freien Willen. De libero arbitrio, München 1987, S. 43.

102 Leinwand, $68 \times 59 \mathrm{~cm}$, Venedig, Galleria dell'Accademia. Den Aspekt der Zeit bei Giorgione hat auch $\mathrm{G}$. Boehm hervorgheoben (Bildnis und Individuum, S. 89ff).

103 Siehe hierzu im Überblick H. U. Asemissen; G. Schweikhart: Malerei als Thema der Malerei, S. 63-67. 
Verkleidung: Das Individuum erscheint hier nicht wie dort in einer gleichsam geborgten Hülle im Kontext einer historischen, mythologischen oder christlichen Szenerie, sondern borgt umgekehrt nun den mythologischen Hintergrund, um die komplexen Abgrenzungen zwischen Individuum und Person bzw. Rolle in den Blick einer erweiterten anthropologischen Selbstbestimmung zu rücken und auf diese Weise das Individuum in seiner komplexen Verborgenheit zu deuten.

\section{Das Bild als Spiegel der Selbstwahrnehmung}

Ein entscheidender Punkt an dieser visuellen Deutung des Menschen liegt darin, daß dabei mehr und mehr auch die Bedeutung der Bezugspunkte und der Rahmenbedingungen seiner Stellung als Individuum erkennbar werden: Im Porträt macht der Maler die Bedingungen der Wahrnehmung des Menschen auf sich selbst in neuer Weise sichtbar.

In keinem Bildnis des frühen 16. Jahrhunderts hat dieser Perspektivwechsel auf den Menschen programmatischer seine künstlerische Gestaltung gefunden, als in Parmigianinos Selbstbildnis von 1523/24 (Abb. 52) ${ }^{104}$. Ohne äußeren Auftrag hat Parmigianino sein Selbstbildnis gemalt, indem er die visuelle Form eines Konvexspiegels direkt auf das Bild projizierte: Die Darstellung ist auf einer runden, sphärisch gewölbten hölzernen Halbkugel ausgeführt, auf der sich um den zentralen Fixpunkt des Gesichtes herum die bewegten Verzerrungen des Spiegelbildes entfalten. Über dem verblüffenden Kunststückcharakter dieses Werks ${ }^{105}$ darf freilich nicht übersehen werden, daß Parmigianino auf diesem Wege die medialen Bedingungen seiner Selbstdarstellung, sowie auch die Wahrnehmung auf sich selbst in grundsätzlich neuer Weise thematisiert: Der Spiegel ist nicht mehr - wie z. B. in der Darstellung des Selbstbildnisses der Malerin Marcia (Abb. 39)-lediglich als notwendiges Hilfsmittel und motivisches Versatzstück abgebildet, sondern er wird als Instanz der Reflexion der Wahrnehmungs- und Darstellungswege dieses Porträts der medialen Struktur des Bildes insgesamt eingeschrieben: Der Mensch bekommt hier im Blick auf sich selbst die Relativität seiner eigenen Wahrnehmung mit in den Blick! Parmigianinos Selbstbildnis steht im Prozeß der Individualisierung als Schlüsselbild an einem historischen Wendepunkt der anthropologischen Selbstreflexion, an dem das Individuum die Relativität seiner Perspektive auf sich selbst verstärkt erkennt und in neuer Form im Medium der Malerei reflektiert. An diesem Punkt der Gattungsgeschichte sind alle wesentlichen Elemente in der Genese des neuzeitlichen Porträts und Selbstporträts erschlossen, die kopernikanische Wende im Prozeß der Individualisierung und in der Genese des neuzeitlichen Bildniskunst ist vollzogen,

04 1523/24, Holzkalotte, Durchmesser 24,4 cm, Wien, Kunsthistorisches Museum, Inv. Nr. 286.

105 Martin Warnke (Der Kopf in der Hand, in: Werner Hofmann: Zauber der Medusa. Europäische Manierismen, Wien 1987, S. 55-61, S. 56f.) interpretiert das Selbstbildnis als Kuriosität im Dienste einer auf öffentliche Wirksamkeit zielenden Künstlerstrategie. 